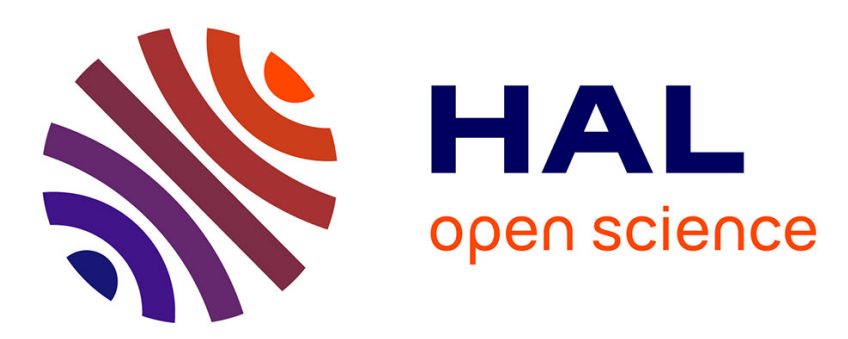

\title{
An evaluation of climatological data in the Indian Ocean area
}

Pascal Terray

\section{To cite this version:}

Pascal Terray. An evaluation of climatological data in the Indian Ocean area. Journal of the Meteorological Society of Japan, 1994, 72 (3), pp.359-386. hal-01336302

\section{HAL Id: hal-01336302 \\ https://hal.science/hal-01336302}

Submitted on 22 Jun 2016

HAL is a multi-disciplinary open access archive for the deposit and dissemination of scientific research documents, whether they are published or not. The documents may come from teaching and research institutions in France or abroad, or from public or private research centers.
L'archive ouverte pluridisciplinaire HAL, est destinée au dépôt et à la diffusion de documents scientifiques de niveau recherche, publiés ou non, émanant des établissements d'enseignement et de recherche français ou étrangers, des laboratoires publics ou privés. 


\title{
An Evaluation of Climatological Data
}

\section{in the Indian Ocean Area}

\author{
By Pascal Terray \\ Institute of Geoscience, University of Tsukuba, Tsukuba, Ibaraki 305, Japan \\ (Manuscript received 16 June 1993, in revised form 15 February 1994)
}

\begin{abstract}
This paper presents evidence that both land-records and marine products currently used to assess the interannual and decadal variability of the monsoon system are subjected to important systematic errors due to non-climatic factors.

The main inhomogeneities in the NCAR's World Monthly Surface Climatology during the 1900-1984 period affect all Sea Level Pressure (SLP) tirne series over the Indian subcontinent. These discontinuities are mainly linked to the non-consideration of changes in the time of observation between sample periods when the data have been compiled at NCAR. The main example of such discontinuity is observed in 1961 with the change from the World Weather Records collection to the Monthly Climatic Data for the World series.

Systematic biases are also revealed for Sea Surface Temperature (SST), Air Temperature (ART) and SLP ship-measurements compiled over the Indian Ocean during 1900-1986. The main spurious jumps occur around 1932 for SLP, 1940 for both SST and ART, and 1954 for SST sampled in the east Arabian Sea and the Bay of Bengal. In addition, an artificial trend contaminates SST reports during 1954-1976. Though no attempts have been made to determine the exact causes responsible for these inhomogeneities, there is little doubt about their origins because all these dates and trends are in phase with important changes in the composition of "source-decks" merged into the marine dataset, and do not agree with fluctuations of corrected SLP and temperature measurements along the coasts of the Indian subcontinent. Finally, substantial biases in resolution of the annual cycle can be expected for all the parameters because the sampling over the Indian Ocean has a strong seasonal dependence after 1950. Many inconsistencies in the observational picture of interannual SST variations over the Indian Ocean are thought to be linked to such data problems.

A comparison between land and marine trends has however suggested the existence of some significant decadal-scale fluctuations in the Indian region during the 1900-1986 period. These true climatic happenings include prominently a warming temperature trend and a general SLP decrease over both land and ocean during 1900-1939, and a sudden warming in the Indian Ocean after 1976. This recent warming does not affect the interior of the Indian subcontinent and is in phase with persistent positive SLP anomalies for the whole Indian sector. This corroborates the evidence of a climatic change in the Indian Ocean after 1976 (Nitta and Yamada, 1989).
\end{abstract}

\section{Introduction}

Within the scientific community, the Indian Ocean is now widely recognized as a key-factor for explaining the low-frequency variability of the global climate system (Yasunari, 1991). Almost two decades ago, Krishnamurti (1971) first demonstrated that the Asian summer monsoon is one of the most energetic features of the climate system and that release of latent heat by monsoon rainfall plays an important role in forcing the global atmospheric circulation

(C) 1994, Meteorological Society of Japan even at midlatitudes. As another illustration, there is now a growing body of evidence that the El-Nino Southern Oscillation (ENSO) phenomenon cannot be fully understood without consideration of the Indian Ocean basin, because low-frequency climatic anomalies first appear in the Indian Ocean and then propagate eastward into the Pacific (Barnett, 1991; Rasmusson et al., 1990). Moreover, this typical evolution of climatic anomalies in the tropical band is a very favorable condition for triggering the ENSO events (Yasunari, 1990; Barnett, 1991).

Despite persuasive evidence of the great impact of the monsoon system on low-frequency variability of 
the global climate system, our understanding of lowfrequency modes of monsoon circulation anomalies is still lacking. Particularly, it is very difficult to understand how low-frequency anomalies can exist in the Indian Ocean because nowhere else in the world the annual cycle is stronger than it is in the Indian Ocean basin. For example, the surface wind field in this region is characterized by a complete reversal of the wind direction from northern summer to northern winter, and the Somali oceanic current near the east African coast also reverses. It should be emphasized now that such a strong annual cycle is likely detrimental to the evolution of interannual climatic anomalies. Thus, if we argue, as many scientists do now, that low-frequency modes of monsoon circulation exist, we must also explain the physical processes which are responsible for the persistence of lowfrequency anomalies in spite of the strong seasonal signal.

Before addressing this matter in greater detail, a critical evaluation of the climatological record (both land-based stations and ship-observations) currently available to study the monsoons is absolutely needed. Although many studies have attempted to assess the quality of climatological data over the Pacific Ocean in relation to ENSO phenomenon and its modeling (Wright, 1986, 1988; Morrissey, 1990), very few papers have focused on providing such a careful examination of bias problems over the Indian Ocean. See however, Barnett (1984) or Rao and Goswami (1988) who give some preliminary investigations of SST fields over the Arabian Sea and the Bay of Bengal. Both of these studies strongly suggest that important inhomogeneities have occurred in SST records. In our opinion, climatological data (both land-records and ship-observations) are too often used without proper assessment of the quality and homogeneity of the records, thereby invalidating the results finally obtained and adding confusion to our knowledge of climatic phenomena. Many of the inconsistencies and uncertainties in the observational picture of interannual monsoon variability (Shukla, 1987) are thought to be due to such problems, as we will see. The validation of the SST warming trend starting in the 1950s over the Indian Ocean (Nitta and Yamada, 1989; Wolter and Hastenrath, 1989) represents a major issue in the context of the persistent drought in Subsaharan Africa since some associations between this drought and the warming over the Indian Ocean have been suggested (Hastenrath and Wolter, 1992). This paper represents a contribution toward solving some of these data problems. This is mainly a technical paper addressing the problem of instrumental trends and discontinuities in climatological data, with the objectives of providing some warnings about the bad quality of many data sources currently used to assess interannual and decadal variations of the monsoon system.
The paper will follow this guideline: land-records and ship-observation products are documented and criticized in sections 2 and 3, respectively. Section 4 gives a detailed comparison of corrected land-records with uncorrected marine series to assess the exact origin of the trends and jumps observed in the ship dataset. Finally, a preliminary statistical analysis of the SST and ART fields in the Indian Ocean during the 1954-1976 period is presented in section 5 to demonstrate the necessity of applying corrections to the SST data even during recent decades. Conclusions follow in section 6 . Technical details about the statistical methodology used in the paper are summarized in two appendices.

\section{The Land Dataset}

In this section, a statistical evaluation of NCAR's World Monthly Surface Station Climatology (WMSSC, e.g., Wulber et al., 1984; Shea and Spangler, 1985), a standard product for studying monsoon variability (Weare, 1979) as well as its relation to the ENSO phenomenon (Trenberth and Shea, 1987), is presented.

First, monthly time series of Sea Level Pressure (SLP; 59 stations), surface air Temperature (T; 73 stations) and rainfall (73 stations) originated from various countries in the Indian sector were extracted from NCAR's magnetic tapes (Wulber et al., 1984). This data collection covers the period 1900-1980, but has been extended here to 1984 with published data in the Monthly Climatic Data for the World (MCDW; US Weather Bureau, 1981-1984). The number of missing months reaches $40 \%, 23 \%$ and $17 \%$ for the SLP, $T$ and rainfall parameters, respectively. Moreover, many of the records thus compiled, contain physically implausible values or suspicious jumps from one decade to another, especially for SLP and $\mathrm{T}$ time series. Using another version of the NCAR's WMSSC, Trenberth and Shea (1987) reached the same conclusions and they produced a plot of the SLP time series at Poona with a large inhomogeneity around 1960. In the same way, Weare (1979) noted a quite suspicious jump occurring at the same date on the time series associated with his EOF analysis of monthly SLP anomalies for selected Indian stations. He attributed this discontinuity to some change in the method of reducing station pressure to sea level at the Indian Meteorological Department (IMD). On the other hand, Trenberth and Shea (1987) suggested that "the problem is thought to be due to the fact that data contained within the WMSSC are periodically updated with reprocessed data spanning a decade. When the data are reprocessed different algorithms may be used causing the inconsistencies" (Trenberth and Shea, 1987, p3093).

In order to realize the problem and find some clues for correcting the data, Table 1 summarizes the results of the Kruskal-Wallis test (Conover, 1980; see 
Table 1. Percentages of Kruskal-Wallis tests significant at the $5 \%$ probability level for each month and parameter before the correction of the land data.

\begin{tabular}{|c|c|c|c|c|c|c|c|c|c|c|c|c|c|}
\hline \multicolumn{14}{|c|}{ TABLE 1} \\
\hline \multicolumn{14}{|c|}{$\begin{array}{c}\text { \% OF KRUSKAL-WALLIS TESTS SIGNIFICANT } \\
\text { AT THE 5\% PROBABILITY LEVEL } \\
\text { BEFORE THE ADJUSTMENT PROCEDURE }\end{array}$} \\
\hline \multirow[t]{2}{*}{ VARIABLE } & \multicolumn{13}{|c|}{ MONTH } \\
\hline & 1 & 2 & 3 & 4 & & 5 & 6 & 7 & 8 & 9 & 10 & 11 & 12 \\
\hline PRESSURE & 96 & 85 & 91 & 93 & & 0 & 89 & 90 & 92 & 95 & 93 & 97 & 93 \\
\hline TEMPERATURE & 26 & 24 & 23 & 24 & & 2 & 25 & 29 & 30 & 28 & 30 & 27 & 28 \\
\hline RAINFALL & 16 & 14 & 12 & 15 & & 6 & 12 & 13 & 12 & 12 & 14 & 13 & 13 \\
\hline
\end{tabular}

Appendix A) applied to the different decades for each month, each parameter and each station (a total of 7380 series). The null hypothesis of the test states that the different decade samples for each station, parameter, month subseries are drawn from the same population (not necessarily normal) with an identical mean. The Kruskal-Wallis procedure is in fact very useful here because it is a nonparametric test sensible to jumps in the mean of the different samples, moreover it allows the presence of any number of missing values in the series involved, as it is the case here. The percentages of cases where the null hypothesis is rejected at the 5\% level are reported in Table 1 for each month and each parameter. The results clearly show the generality of the bias problem for the SLP data and to some degree for the temperature records. Thus, we are led to reexamine the history of the NCAR's tapes for resolution of this issue.

First, it must be noted that there is usually no indication of a station move or change in elevation associated with the different inhomogeneities in the NCAR's tapes. More to the point, a vital piece of information is that the NCAR's tapes result from the compilation of different published sources, mainly the World Weather Records collection for the period 1900-1960 (WWR; Smithsonian Institution, 1927, 1934, 1947; US Department of commerce, 1959, 1967) and MCDW for the 1961-1980 period (US Weather Bureau, 1961-1980).

In fact, each WWR volume spans approximately one decade and gives plenty of notes about changes in times of observation, in observational, practices or station moves. In most of the cases, but not all, corrections have been carried out on published data for each volume, but data from different volumes are not necessarily homogenized. As an example, IMD has adopted the 1953 International Barometric Conversion proposed by the World Meteorological Organization in 1956 and the 1951-1960 data have been corrected in the WWR's tables. Moreover, the authors of this volume suggest that a series of correc- tions (between -0.1 and -0.3 millibars) has consequently to be applied to the data of the previous WWR's volumes for preserving the continuity of the SLP Indian time series. More generally, the Indian SLP data published in the WWR's collection covering the period 1900-1960 have been reduced to 8 hours Indian Local Time (ILT), except for some stations during the 1951-1960 decade. For Pakistan SLP data after World War II, the series have been reduced to $8 \mathrm{H} 30$ Indian Standard Time (IST) during 1941-1950, but the decade 1951-1960 has not been adjusted consequently. In the same fashion, pressure data for Sri Lanka have not been corrected at all. As NCAR's tapes are the exact reproduction of the published tables of the WWR's collection for the 1900-1960 period and none of the corrections provided separately in each volume have been carried out when the data have been compiled, all the above changes are sources of systematic errors contributing to the bias summarized in Table 1. It explains also why many of the discontinuities occurred between decades as each WWR's volume spanned a decade and is adjusted separately.

Unlike the WWR's, the MCDW volumes give no useful technical information about the data. However, the fact that all Indian SLP time series exhibit a big jump at the start of this source in the magnetic tapes suggests indubitably that the times of observation have changed between the two sources. To examine this aspect further, we looked directly at the India Weather Review (Monthly Weather Reports) collection (IWR) of IMD and found that pressure data published in the MCDW volumes were calculated from $(8 \mathrm{H} 30+17 \mathrm{~h} 30) / 2$ IST instead of $8 \mathrm{H} 30$ IST or $8 \mathrm{H}$ ILT for the WWR's data. This fact introduces a new systematic error in SLP series due to the diurnal cycle which undergoes quite strong spatial and seasonal variations in the Indian sector.

For correcting all these systematic biases in the data, many correction formulae were derived. First, all the pressure data before 1960 were systematically reduced to 8H30 IST using the WWR's notes and other useful information provided by the IWR volumes. Particularly useful in these pressure adjustments are the ILT and IST differences for all the stations on the Indian subcontinent. This information is available in the IWR volumes published before 1940. In the same fashion, the data have been adjusted for the discontinuity resulting from the adoption of the 1953 International Barometric Conversion by using the WWR's notes. To adjust SLP time series for the main 1961 discontinuity, a separate examination has been carried out. More precisely, the monthly diurnal amplitude for each station was computed to get an estimate of the bias between the WWR and MCDW collections. These computations have been done on the 1961-1970 decade with the help of some data available through the IMD publications. The resulting corrections have been added to the MCDW 
Table 2. As in Table 1, but after the correction of the SLP and temperature data.

\begin{tabular}{|c|c|c|c|c|c|c|c|c|c|c|c|c|c|}
\hline \multicolumn{14}{|c|}{ TABLE 2} \\
\hline \multicolumn{14}{|c|}{$\begin{array}{c}\text { \% OF KRUSKAL-WALLIS TESTS SIGNIFICANT } \\
\text { AT THE 5\% PROBABILITY LEVEL } \\
\text { AFTER THE ADJUSTMENT PROCEDURE }\end{array}$} \\
\hline \multirow[t]{2}{*}{ VARIABLE } & \multicolumn{13}{|c|}{ MONTH } \\
\hline & 1 & 2 & 3 & & 4 & 5 & 6 & 7 & 8 & 9 & 1 & \begin{tabular}{|l|l}
0 & 11
\end{tabular} & 12 \\
\hline PRESSURE & 22 & 19 & 20 & & 1 & 0 & 20 & 20 & 19 & 2 & 2 & 21 & 21 \\
\hline TEMPERATURE & 25 & 2 & 422 & & 2 & 3 & 25 & 28 & 29 & 2 & & 27 & 27 \\
\hline
\end{tabular}

data to reduce them at 8 H30 IST. Similar computations have been undertaken for SLP data of Sri Lanka on the shortest 1955-1960 period. Approximate corrections have also been applied to SLP data of Pakistan and Bangladesh by using corrections computed on nearby Indian stations. The validity of our approach seems justified by very small standarderrors $(\sim 0.2 \mathrm{mb})$ of the bias samples compared to monthly mean bias values $(2-3 \mathrm{mb})$ during the 1961 1970 decade. At the same time, temperature corrections given in WWR volumes and not yet applied to NCAR's temperature data have been carried out. No corrections have been applied to rainfall data. To verify the overall effect of our various corrections, the Kruskal-Wallis test has been applied again on globally adjusted time series. The results (Table 2) clearly show that most of SLP records are now basically sound. The corrections have not greatly improved the results of the tests for temperature records. A detailed investigation reported in Terray (1992) has shown that these significant tests are linked to some trends to warmer temperature over some areas of the Indian subcontinent and not to data problems. A discussion of these warming trends is given in section 4 .

\section{The Marine Dataset}

In recent years, systematic errors have been repeatedly noted for all kind of meteorological variables (e.g., Barnett, 1984; Ramage, 1987; Wright, 1986, 1988; Morrissey, 1990; Cardone et al., 1990, among others) extracted from various marine datasets such as the Comprehensive Ocean Atmosphere Data Set (COADS, Woodruff et al., 1987) or the TDF-11 family tapes of the National Climate Data Center [Asheville, north Carolina, USA, documented in NCDC (1968)]. Particularly, the figures of Barnett (1984) suggest that the Indian Ocean is perhaps the worst case among all the oceans in respect to the bias and trend problems for the SST fields, a key variable in recent discussion of interannual and decadal variability in the Indian Ocean. The goal of this section is the detection of the discontinuities and trends in the ship dataset which are related to these data problems.

\section{3.a Data}

Our marine dataset results from the merging of three different sources:

-The classical TDF-11 marine deck of the National Climate Data Center.

-The Dutch file which represents the Netherlands contribution to the Historical Sea Surface Temperature Data (HSSTD) project (Barnett, 1984).

-A ship dataset obtained directly from the United Kingdom Meteorological Office.

It should be emphasized that new products, such as COADS of the United Kingdom Meteorological Office SST dataset (UKMO; Bottomley et al., 1990) draw largely from the same sources as our marine dataset does, as far as the Indian Ocean is concerned. Duplicate reports in at least two of the above referenced sources were rejected and monthly mean fields were constructed on a $2^{\circ} \times 2^{\circ}$ degree mesh for SST, ART and SLP. The period used here covers 1900 1986 and the domain of study extends from $30^{\circ}$ to $100^{\circ}$ E Longitude and from $30^{\circ} \mathrm{S}$ to $30^{\circ} \mathrm{N}$ Latitude. For the period 1954-1976, this ship-observation dataset is essentially the same as in Cadet and Diehl (1984). After elimination of physically unreasonable values, the standard deviation of data was estimated at grid points where at least three observations were available. Then as a first quality control check, individual observations deviating by more than 2.5 standard deviation of the grid point mean value were rejected. This procedure was applied twice and the means at each grid-point were recomputed.

To assess the coverage of the ship date/Fig. 1a shows the distribution of the average monthly number of SLP observations in each box during 19001986 and Fig. 1b gives the annual mean number of marine reports over the entire domain during the same time interval. It can be seen that the data coverage is dense only along the main shipping lanes. The data are especially scant over most of the Southern Hemisphere Indian Ocean. The sharp decrease of the report's number during both World Wars should be also emphasized as an important data problem.

The noisy nature of the ship observations was partially overcome by averaging the data over different key-areas located on the main shipping routes (Fig. 2) and for the whole Indian Ocean as delimited in Fig. 2. The monthly time series were determined as follows:

(i) First, the 1954-1976 interval (a well-sampled period for all the domains) was used as a reference period for calculating a climatology for each month and each $2^{\circ}$ box, provided that data for at least 10 years with more than 5 observations per month were available in the period. The monthly means for each $\mathrm{i}$ grid point and $\mathrm{j}$ month were computed as a weighted average 


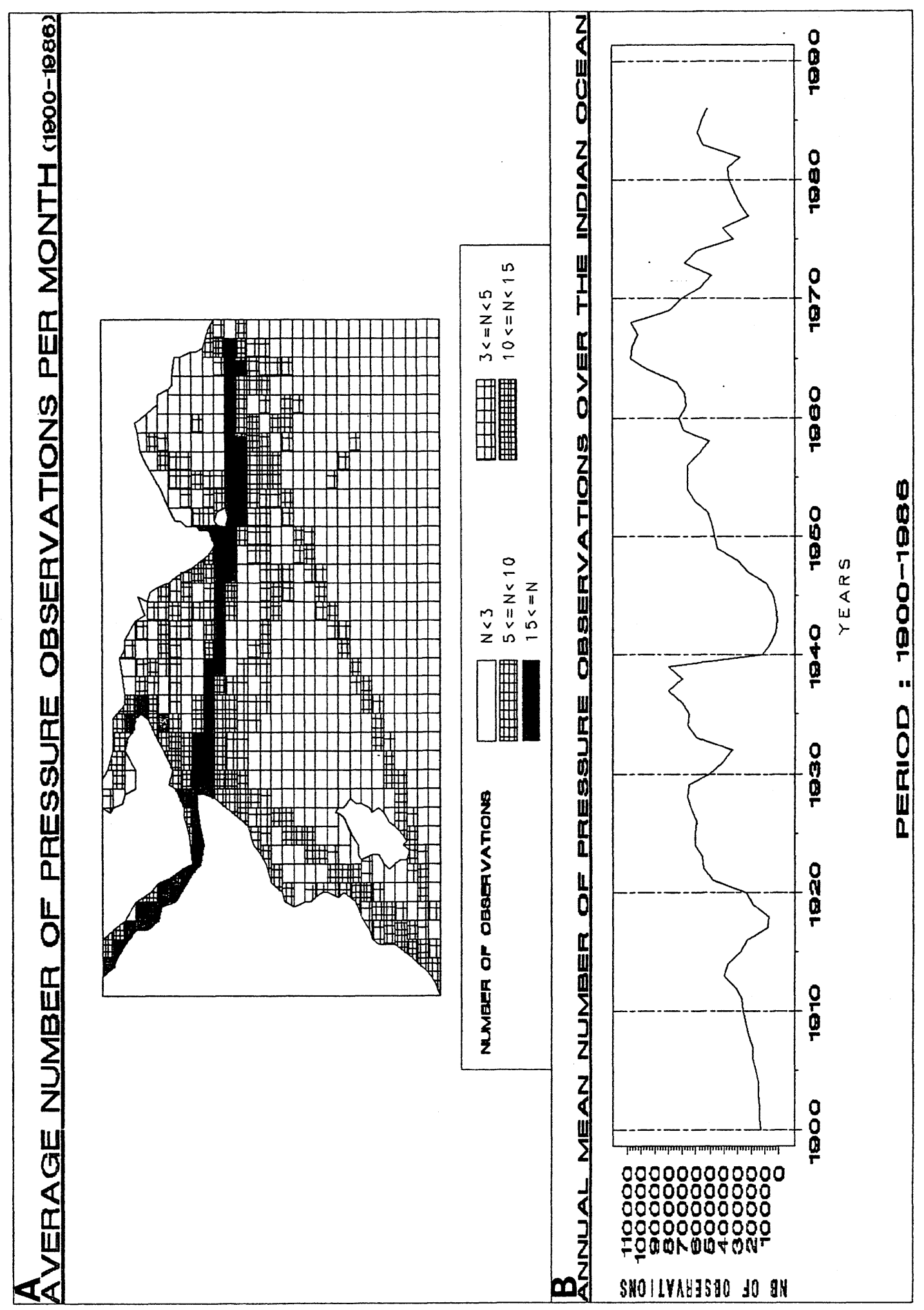




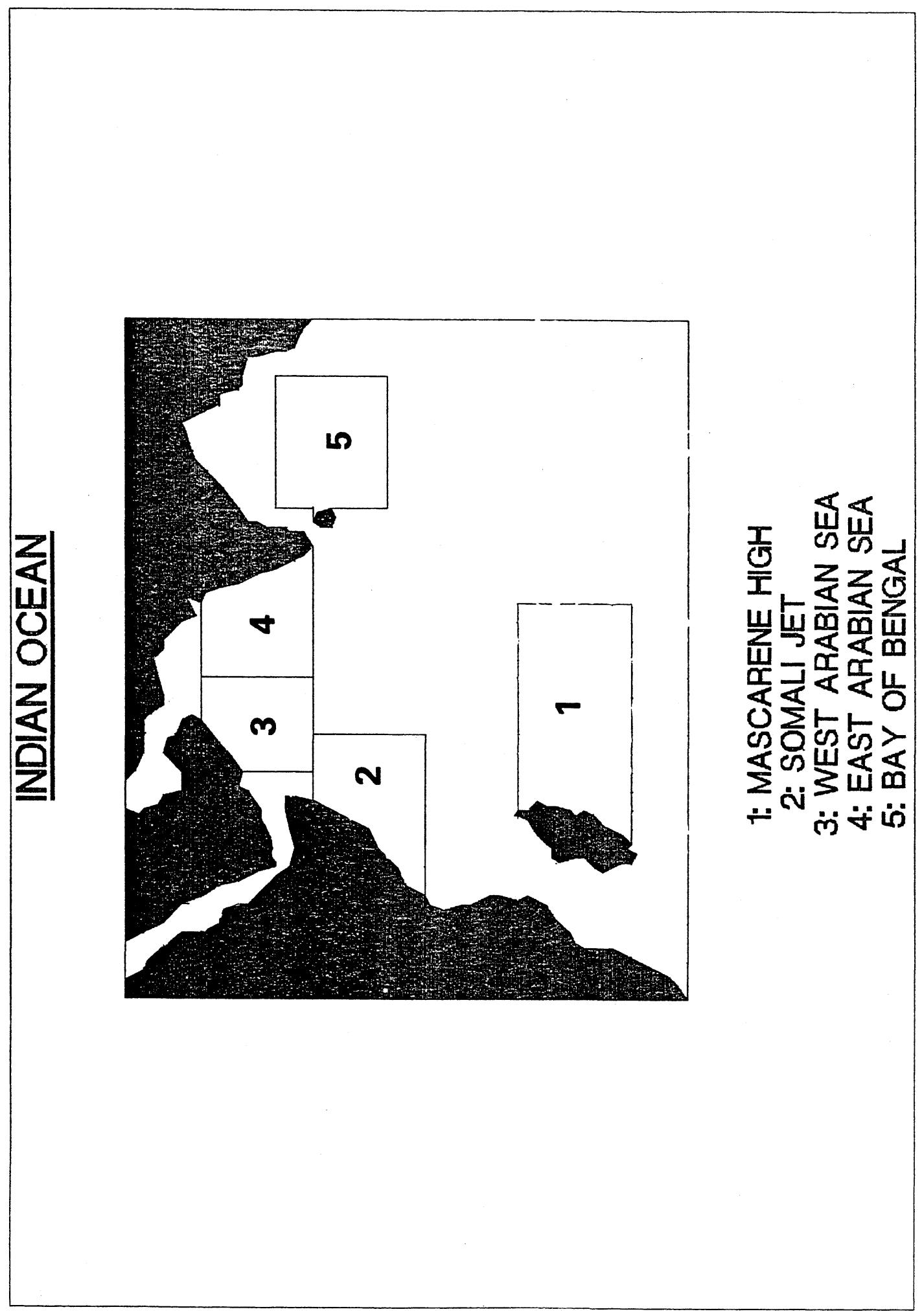




$$
\begin{aligned}
& \overline{\mathbf{X}}_{i j}=\sum_{k=1954}^{1976} \mathbf{W}_{i j k} \mathbf{X}_{i j k} / \sum_{k=1954}^{1976} \mathbf{W}_{i j k} \\
& \text { where } \quad \mathbf{W}_{i j k}=1-\exp \left(-\mathbf{N}_{i j k} / 5\right)
\end{aligned}
$$

Here $\mathbf{X}_{\mathrm{ijk}}$ is the value computed for the ith box, jth month and kth year. $\mathbf{N}_{i j k}$ is the number of shipobservations used in computing $\mathbf{X}_{\mathrm{ijk}}$. $\mathbf{W}_{\mathrm{ijk}}$ is in the neighborhood of 1 if $\mathbf{N}_{\mathrm{ijk}}>10$ and near 0.5 if $\mathbf{N}_{\mathrm{ijk}}$ equals 5 . This weighting scheme has proved to enhance the quality and continuity of the climatology compared to a simple linear average approach. No attempt has been made to interpolate the climatology for the data-void boxes during the reference period.

(ii) After this first step, time monthly anomaly series for each $2^{\circ}$ box during the 1900-1986 period were computed by simply subtracting from each value this climatology, provided that neither the datum nor the climatology was missing. These anomalies were then subsequently spatially averaged over the different domains and the whole Indian Ocean with the same weighting scheme (e.g., $\mathbf{W}_{\mathrm{ijk}}$ ) as used in the computation of the climatology. These SST, ART and SLP time series were then subjected to various statistical analyses to assess their consistency.

\section{3.b Exploratory data analysis of the bias-trend problem}

The starting point of this section is the identification of the main suspicious jumps and trends which can be observed in the marine datasets and need a careful examination. To this end, the different monthly anomaly time series were analyzed with the X11 monthly additive scheme (Kendall and Ord, 1990; see Appendix B), a powerful technique for describing a time series. In the procedure, the analyzed $\mathbf{X}_{\mathrm{t}}$ monthly time series is decomposed into three terms

$$
\mathbf{X}_{\mathrm{t}}=\mathbf{T}_{\mathrm{t}}+\mathbf{A}_{\mathrm{t}}+\mathbf{I}_{\mathrm{t}}
$$

The $\mathbf{T}_{\mathrm{t}}$ term is used to quantify the trend and low-frequency variations in the time series. The $\mathbf{A}_{t}$ term describes the annual cycle and the $\mathbf{I}_{t}$ term refers to the "irregular" fluctuations of the curves. All the terms are estimated with specific moving averages of various lengths and appropriate procedures for outlier detection (see Appendix B). In our analysis problem, the resulting components of each monthly anomaly time series can be interpreted as follows:

-The trend component $\mathbf{T}_{\mathrm{t}}$ can be used to assess the trends as well as the jumps in the anomaly series if we take care of the length of the moving average used to estimate this component. That is, each jump in the time series will provoke a sudden change in the slope of the trend component for a period centered on the discontinuity. The length of this period is directly dependent on the length of the moving average used to estimate the trend component, $\mathbf{T}_{\mathrm{t}}$. As a 23-term moving average has been used here (see Appendix B), this time interval will be of 2 years centered on the discontinuity.

-Taking into account the fact that the analyzed monthly series is formed with anomalies, no annual cycle must appear if the detrended time series is purely stationary. Consequently, any detected annual cycle on the $\mathbf{A}_{\mathrm{t}}$ component can be used to assess changes in the seasonal cycle of the fields. These non-stationary characteristics of the fields can be interpreted in two ways. They could be the result of a climatic modulation of the annual cycle as well as the consequence of a seasonally varying bias in the data. The X11 method by itself doesn't allow us to distinguish between these two possibilities. It should be noted that a trend restricted to one season will also give raise to important fluctuations in this annual component since this trend can be interpreted as a modulation of the annual cycle of the fields.

-Finally, the irregular term $\mathbf{I}_{\mathrm{t}}$ can be used to assess the level of noise in the data, though this term can also contain some signal in a climatological sense.

Figures. 3 and 4 give the results of the analysis for the SST and ART time series over the whole Indian Ocean. The analysis for the SST anomaly series over the Bay of Bengal is reported in Fig. 5. The monthly number of observations is also plotted on the bottom of each figure as an aid for interpreting the results and detecting accurately any change in the composition of the "source-decks" contributing to the time series. The trends for the SST and ART time series over selected areas are shown in Fig. 6 without the other components of the model.

Physically, the SST and ART trends should fluctuate in parallel in the tropics and any deviation from this rule is a strong indication of the presence of artificial trends in the SST or/and ART series (Ramage, 1984). Moreover, the difference between the SST and ART trends must stay roughly constant over each area if there is no climatic change or important bias during the period. Any significant variation in this difference during a period of 1 or 2 decades, or more, implies important fluctuations in latent and sensible heat fluxes which indicate a climatic change if we accept the hypothesis of the correctness of the SST and ART data, or alternatively suggests the presence of artificial biases in the data. Following these guidelines, four or five different subperiods can be detected on Fig.6:

-The period 1900-1939 where the difference between the SST and ART trends is more or less constant and both variables show a trend to warmer temperatures.

-The period 1940-1945, where both variables were tremendously higher than before, but also unreliable because of a large noise level due to the lack of 


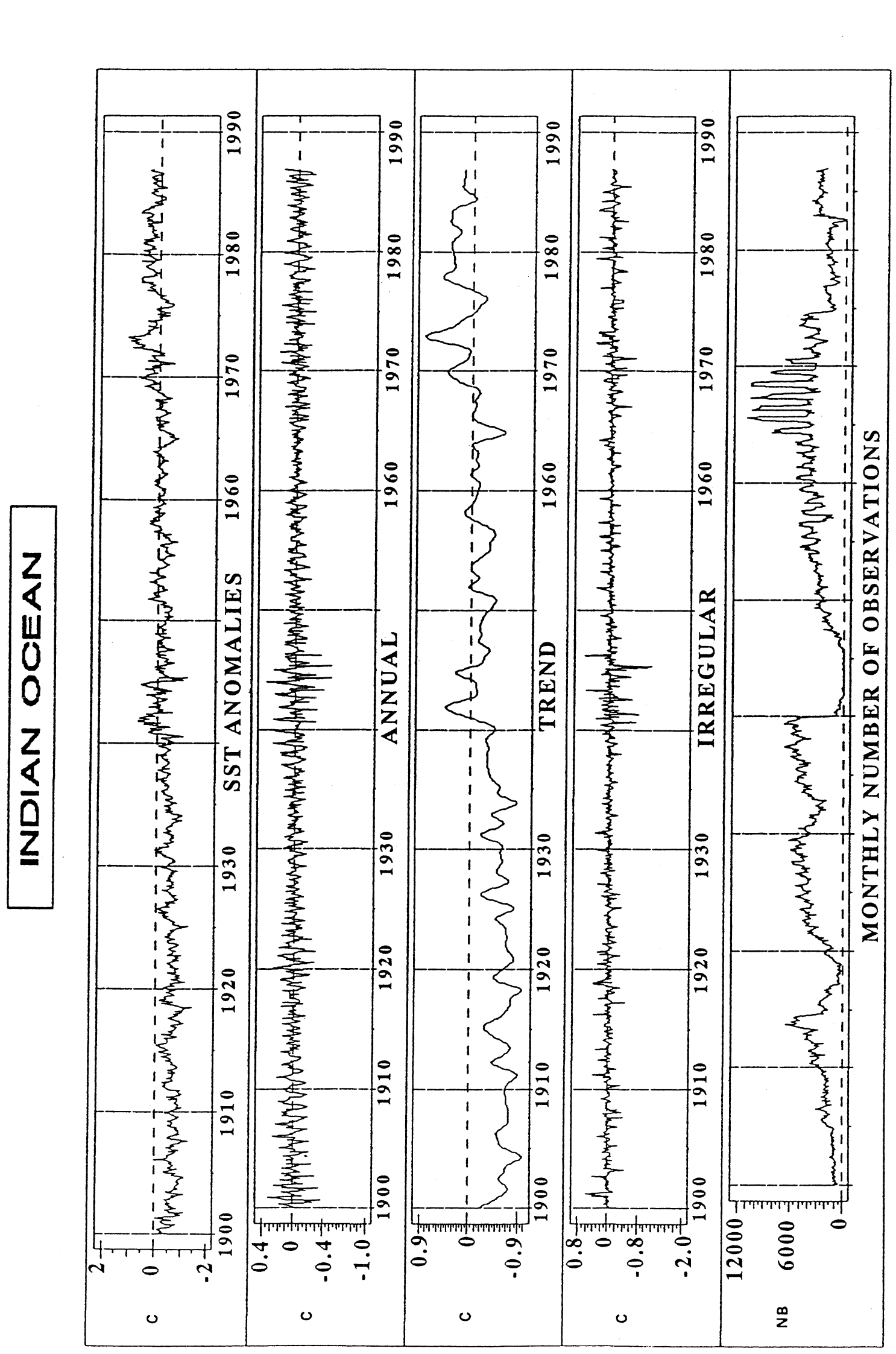




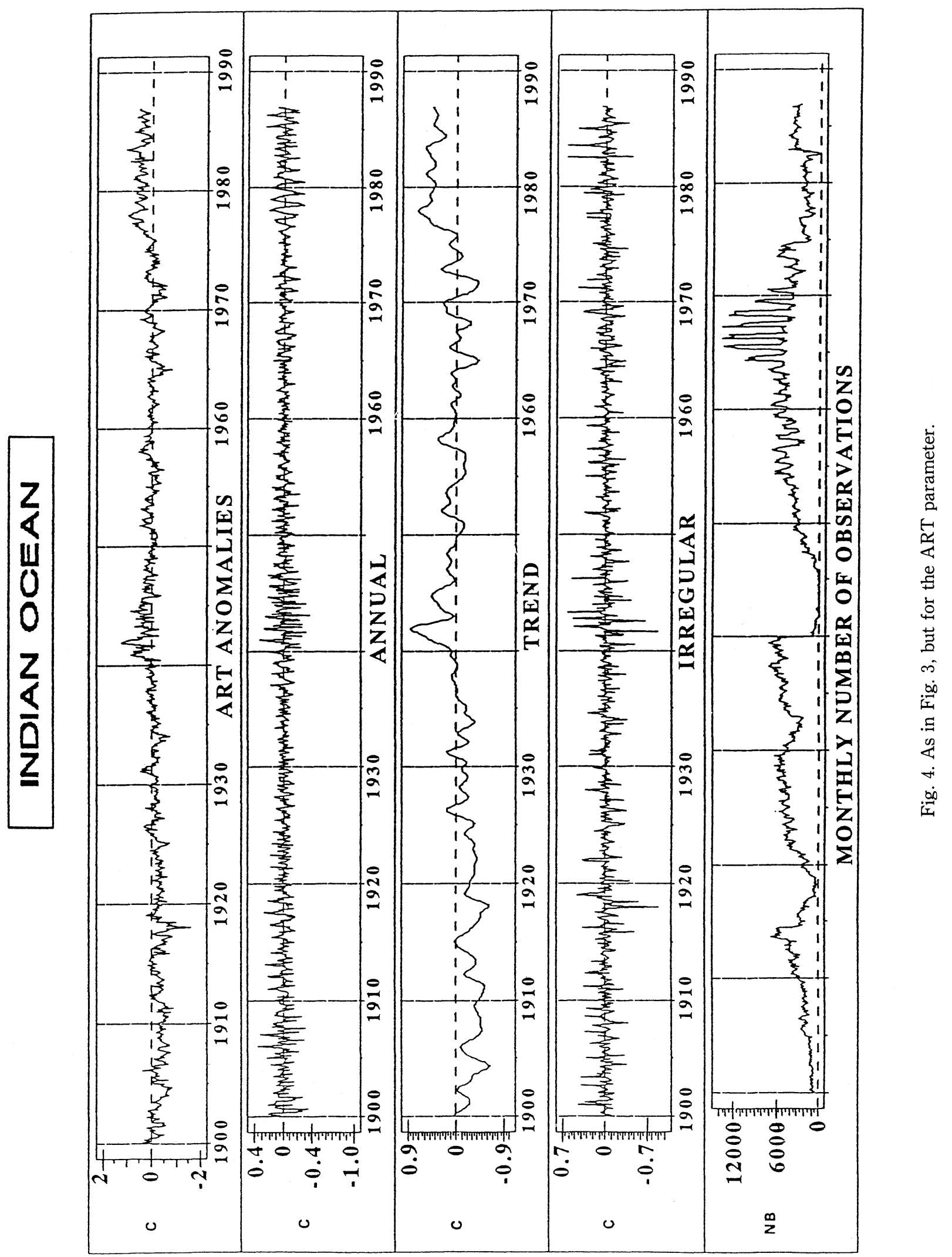




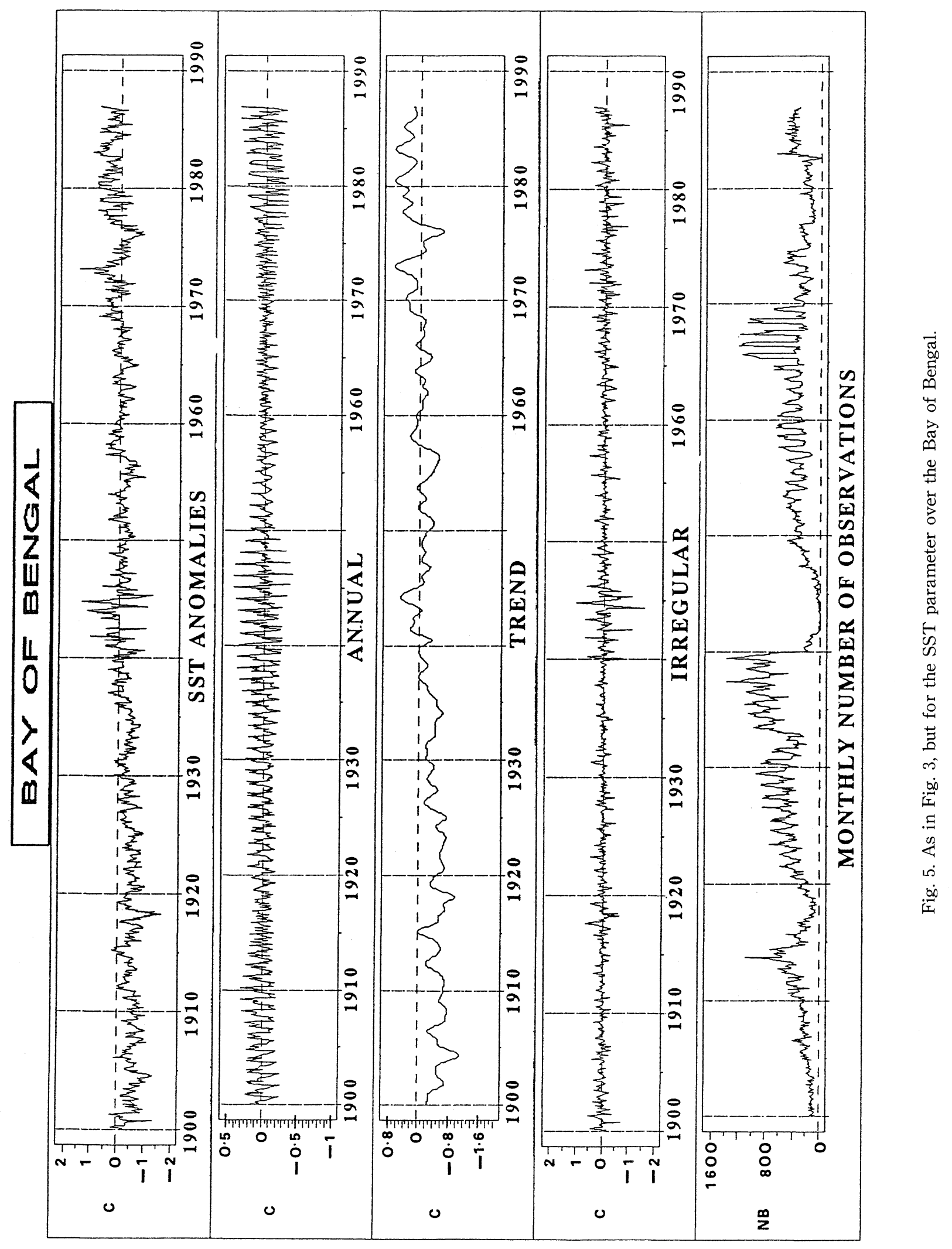




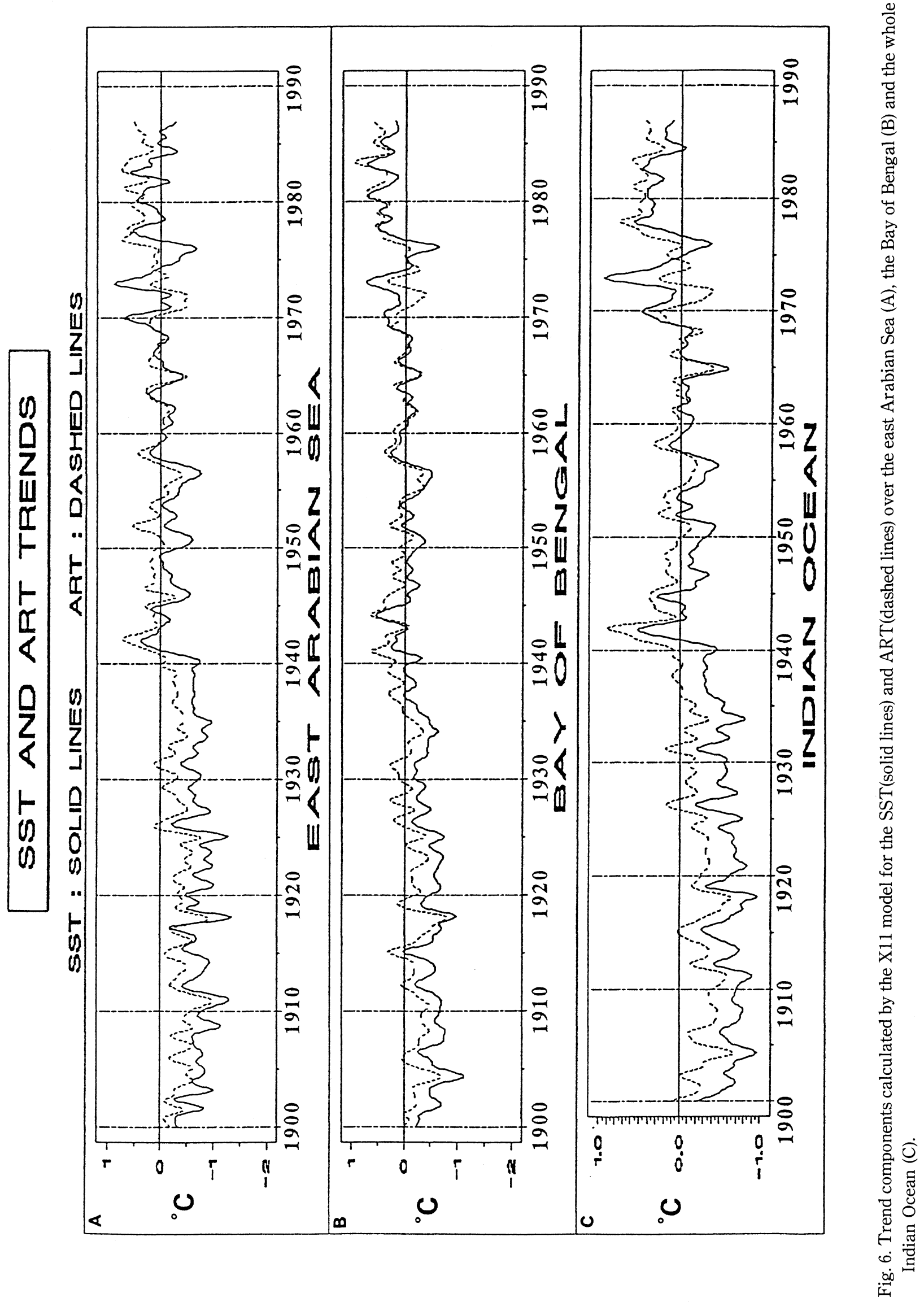


ship-observations (see Fig. 3 and 4). There is also a significant change in the difference between the SST and ART trends during this interval.

-The 1946-1953 (or perhaps 1946-1956 for some areas) interval where both trend components are rather flat with a constant difference. However, this difference is not the same as those observed during the two preceding periods or the succeeding one's. A careful examination of the various SST and ART trend components in each domain shows that this effect is more pronounced in the east Arabian Sea and the Bay of Bengal and that the change in the difference between the SST and ART trend components is linked to subtle discontinuities in the SST series (see Fig. 5).

-The 1954-1976 interval where the SST trends become substantially "warmer" than the ART curves with a particularly huge difference in the beginning of the 1970's. There is a clear indication of the presence of an instrumental trend in the SST or ART fields during this period since the two trend components do not fluctuate in parallel.

-And finally, the most recent decade 1977-1986, where both variables follow again a parallel evolution after a big jump around 1976.

Another problem which has a quite important and pernicious effect is the strong annual cycle in the monthly number of ship-reports over the Indian Ocean (Fig. 3, 4 and 5). These sampling biases, which can be attributed to the success of the shipping techniques in the monsoon area, can also lead to strong systematic errors. In particular, it implies that the means for some months (winter) are greatly less reliable than those for other months (summer and fall), and that caution must be exercised when forming seasonal anomalies over the Indian Ocean because the seasonal series will be biased toward specific months. A direct proof of this assertion can be found in Table 3 where the monthly percentages of variance accounted for by each model's component for the SST series over the whole Indian Ocean are reported. The percentages of variance for the irregular component are higher during the winter months than those observed in summer and fall. These statements are also valid for the SST series computed over the different domains indicated in Fig. 2. On the other hand, the ART fields seem not affected by this sampling problem since the monthly variance explained by the ART irregular component fluctuates independently of the sampling distribution of the reports for the ART grand series (Table 4). This suggests only that the ART reports are too noisy by themselves for clearly demonstrating this sampling problem, but the trend components calculated from the ART fields can still be deteriorated by the sampling biases and therefore be unreliable. This monthly distribution of data seems typical of the Indian Ocean and is not observed in other oceans (see
Table 3. Contribution (\%) of X11 components (Annual, Trend, Irregular) to the monthly variance in the SST Indian Ocean series. The percentages in each lign do not sum to 100 because the X11 component's monthly series are not orthogonal. The mean number of observations (Nobs) contributing to the SST series for each month during the 1900-1086 period is also given as an aid for interpreting the results.

\begin{tabular}{||c|c|c|c|c||}
\hline \multicolumn{5}{|c||}{ TABLE 3 } \\
\hline \hline \multicolumn{5}{|c||}{ CONTRIBUTION (\%) OF X11 COMPONENTS } \\
TO VARIANCE IN THE SST INDIAN OCEAN SERIES \\
\hline \hline MONTH & ANNUAL & TREND & IRREGULAR & NOBS \\
\hline 1 & 10 & 83 & 7 & 2786 \\
\hline 2 & 1 & 83 & 17 & 2456 \\
\hline 3 & 0 & 83 & 19 & 2899 \\
\hline 4 & 0 & 77 & 19 & 2705 \\
\hline 5 & 3 & 81 & 13 & 3551 \\
\hline 6 & 1 & 83 & 12 & 3606 \\
\hline 7 & 16 & 85 & 4 & 3695 \\
\hline 8 & 11 & 86 & 10 & 3707 \\
\hline 9 & 17 & 88 & 2 & 3434 \\
\hline 10 & 1 & 91 & 6 & 2892 \\
\hline 11 & 11 & 90 & 6 & 2747 \\
\hline 12 & 2 & 90 & 15 & 2884 \\
\hline \hline
\end{tabular}

Table 4. Same as in Table 3, but for the ART Indian Ocean series.

\begin{tabular}{|c|c|c|c|c|}
\hline \multicolumn{5}{|c|}{ TABLE 4} \\
\hline \multicolumn{5}{|c|}{$\begin{array}{l}\text { CONTRIBUTION (\%) OF X11 COMPONENTS } \\
\text { TO VARIANCE IN THE ART INDIAN OCEAN SERIES }\end{array}$} \\
\hline MONTH & ANNUAL & TREND & IRREGULAR & NOBS \\
\hline 1 & 19 & 76 & 26 & 3082 \\
\hline 2 & 4 & 77 & 35 & 2866 \\
\hline 3 & 32 & 88 & 11 & 3322 \\
\hline 4 & 20 & 77 & 15 & 3021 \\
\hline 5 & 13 & 79 & 8 & 4071 \\
\hline 6 & 2 & 78 & 15 & 3988 \\
\hline 7 & 1 & 67 & 33 & 4097 \\
\hline 8 & 2 & 77 & 10 & 4116 \\
\hline 9 & 8 & 73 & 7 & 3805 \\
\hline 10 & 1 & 86 & 15 & 3236 \\
\hline 11 & 19 & 85 & 12 & 3101 \\
\hline 12 & 21 & 86 & 14 & 3221 \\
\hline
\end{tabular}

Barnett, 1984; for similar plots over the Pacific Ocean).

In order to confirm more quantitatively the qualitative results given by the X11 procedure, the Kruskal-Wallis test was applied directly to the anomaly series for each parameter/month/domain (see Appendix A). The 1900-1986 period was divided in 4 classes for the computation of the test statistic. For 
Table 5. Probability levels of the Kruskal-Wallis test applied to the SST monthly series computed in the Mascarene (MAS), Somali (SOM), West Arabian Sea (WAS), East Arabian Sea (EAS) and Bay of Bengal (BAY) regions, and in the whole Indian Ocean (IO). The groups of years used in the tests are defined as follows: 1900-1939, 1946-1953, 19541976, 1977-1986.

\begin{tabular}{||c|l|c|c|c|c|c||}
\hline \hline \multicolumn{7}{||c||}{ TABLE 5} \\
\hline \hline \multicolumn{7}{|c||}{$\begin{array}{c}\text { PROBABILITY LEVELS OF THE KRUSKAL-WALLIS TEST } \\
\text { APPLIED TO THE SST SERIES }\end{array}$} \\
\hline MONTH & MAS & SON & WAS & EAS & BAY & IO \\
\hline 1 & 0.68 & 0.0001 & 0.0001 & 0.0001 & 0.0001 & 0.0001 \\
\hline 2 & 0.66 & 0.0006 & 0.0001 & 0.0001 & 0.0001 & 0.0001 \\
\hline 3 & 0.009 & 0.0001 & 0.0001 & 0.0001 & 0.0001 & 0.0001 \\
\hline 4 & 0.22 & 0.0001 & 0.0001 & 0.0001 & 0.0001 & 0.0001 \\
\hline 5 & 0.01 & 0.0001 & 0.0001 & 0.0001 & 0.0001 & 0.0001 \\
\hline 6 & 0.01 & 0.0001 & 0.0006 & 0.0001 & 0.0001 & 0.0001 \\
\hline 7 & 0.0001 & 0.0001 & 0.0003 & 0.0001 & 0.0001 & 0.0001 \\
\hline 8 & 0.01 & 0.0001 & 0.0001 & 0.0001 & 0.0001 & 0.0001 \\
\hline 9 & 0.001 & 0.0001 & 0.0001 & 0.0001 & 0.0001 & 0.0001 \\
\hline 10 & 0.003 & 0.05 & 0.0001 & 0.0001 & 0.0001 & 0.0001 \\
\hline 11 & 0.01 & 0.0001 & 0.0001 & 0.0001 & 0.0001 & 0.0001 \\
\hline 12 & 0.01 & 0.0001 & 0.0001 & 0.0001 & 0.0001 & 0.0001 \\
\hline \hline
\end{tabular}

each monthly series, the classes are 1900-1939, 19461953, 1954-1976, 1977-1986. The 1940-1945 period was eliminated since both the ART and the SST fields are unreliable during this period. The significance levels obtained for each month/domain SST series are summarized in Table 5 . The results for the ART parameter are similar (Table not presented). The results clearly indicate a shift of the monthly means for nearly all areas during one or more subperiods. The main periods contributing to the significance of the tests are 1900-1939 and 1977-1986, in agreement with the results of the X11 procedure. It is noteworthy that the results of the test are less significant for the Mascarene series. This suggests that the decadal variations or the instrumental errors affecting the North and South Indian Ocean are a little different. However, such a result does not inspire confidence because many values are missing in the Mascarene series before 1940. Indeed, the Mascarene region is correctly sampled only during the short 1965-1975 interval and all the other periods can be considered as unreliable because the anomaly series is based on too few ship-observations.

Since the atmospheric response to ocean surface thermal anomalies is important in the tropics, it is interesting now to examine the SLP anomaly series in order to corroborate the "climatic changes" suggested by the SST and ART series. The X11 analysis of the grand SLP anomaly series for the Indian Ocean is presented in Fig. 7. The monthly variance
Table 6. Same as in Table 3, but for the SLP Indian Ocean series.

\begin{tabular}{||c|c|c|c|c||}
\hline \hline \multicolumn{5}{||c||}{ TABLE 6} \\
\hline \multicolumn{5}{|c||}{ CONTRIBUTION (\%) OF X11 COMPONENTS } \\
TO VARIANCE IN THE SLP INDIAN OCEAN SERIES \\
\hline MONTH & ANNUAL & TREND & IRREGULAR & NOBS \\
\hline 1 & 20 & 35 & 42 & 2668 \\
\hline 2 & 28 & 32 & 60 & 2385 \\
\hline 3 & 13 & 31 & 45 & 2767 \\
\hline 4 & 16 & 34 & 37 & 2630 \\
\hline 5 & 19 & 19 & 52 & 3553 \\
\hline 6 & 12 & 17 & 44 & 3467 \\
\hline 7 & 15 & 36 & 47 & 3557 \\
\hline 8 & 34 & 40 & 24 & 3574 \\
\hline 9 & 19 & 64 & 37 & 3305 \\
\hline 10 & 19 & 40 & 27 & 2777 \\
\hline 11 & 26 & 11 & 39 & 2689 \\
\hline 12 & 13 & 36 & 29 & 2754 \\
\hline \hline
\end{tabular}

explained by the different components of the X11 model for this time series are summarized in Table 6 . The SLP variance explained by the trend component seems very low in comparison of the amounts reported for the SST and ART parameters (compare Table 6 with Tables 3 and 4). On the other hand, the irregular component explains a large part of the fluctuations of this grand SLP anomaly series, indicating a high level of statistical noise in ship-recorded pressure measurements over the Indian Ocean. This fact is even more amplified in the X11 analysis of the SLP series computed in the different domains. These first results suggest that the potential problems linked to SLP ship-measurements can give rise to a large noise background, but that the SLP series should be less affected by artificial trends than the SST series. Two important discontinuities are nevertheless apparent in both the anomaly series itself and the trend component presented in Fig. 7. The first occurs around 1932 and the second after 1976 like for the SST and ART parameters. The existence of these discontinuities has been confirmed by the KruskalWallis test applied to each monthly/domain SLP time series with 3 classes defined as follows, 19001932,1933-1976 and 1977-1986, though the SLP jumps seem more seasonally dependent than those observed for the SST and ART parameters (Table not shown).

\section{3.c Discussion}

At first sight, there is a strong indication that most of the variations described in the last paragraph reflect non climatic effects. In particular, a close look at Figs. 3, 4, 5, and 7, shows that all the jumps in the trend components correspond to a big discontinuity in the monthly observations number time series. Such jumps are likely to reflect important changes in the source-decks merged into our historical 


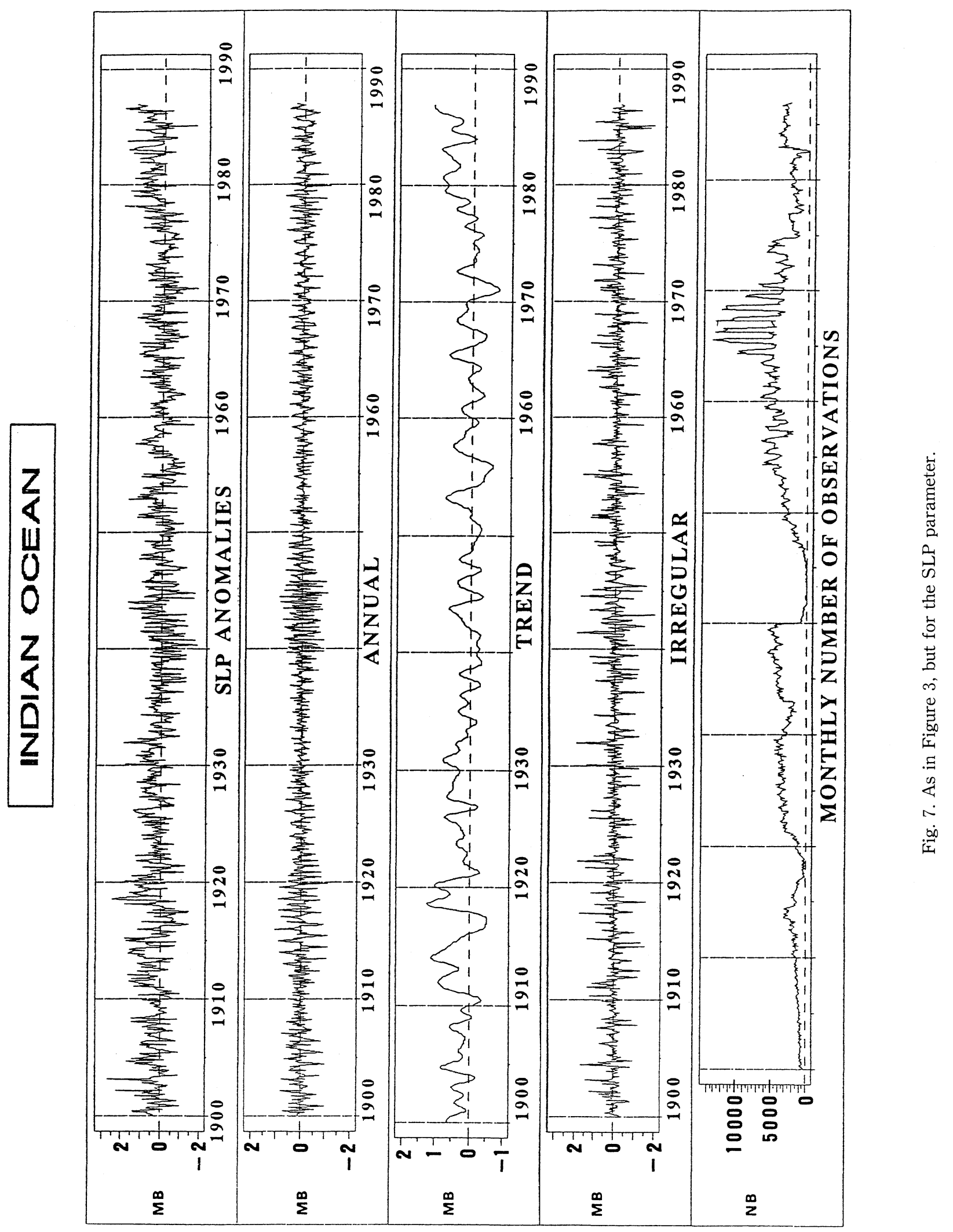


marine dataset and thus probably important changes in the practice or instruments of observations in the ship-reports involved for computing the anomaly series.

For example, it is well-known that most of the ship-reports during 1900-1939 come from European decks which contain a large majority of uninsulated bucket SST measurements which are biased low, while the data after the 1940s are a blend of European, Japanese and US merchant Marine observations, the two later sets being composed mostly of injection or uninsulated bucket measurements which are biased high (Barnett, 1984; Folland et al., 1993). On the other hand, the ART series also show a slight jump around 1940 and this would indicate a real climatic change since the ART data are not subject to the same sources of errors than the SST. Unfortunately, potential biases due to long-term changes in recorded observing times can also explain the 1940's discontinuity in the ART series. During the 1930s there was a shift from SST measurements at 4hourly to 6-hourly intervals in the Indian Ocean (Bottomley et al., 1990), so one wonders if the ART measurements which are much more influenced by such a change have not followed the same evolution. An important result is that there is no indication of important SLP fluctuations around 1940 in the marine dataset. This raised again serious doubts about the origin of the SST and ART "climatic changes" evidenced by Figs. 4, 5, 6 around this date. Fu and Fletcher (1988) argued that this date represents an actual climatic happening in the Asian monsoon region. We strongly suggest that such a claim must await a more definitive proof. Additional evidence for the artificial origin of the 1940's SST and ART jumps will be also presented in section 4 .

As a second example, it has also been recognized that the warmth ART-reports of the 1942-1945 period (see Figs. 4 and 5) are highly unreliable due to some change of the observational practices during World War II (Bottomley et al., 1990).

It is often assumed in many correction schemes (Folland et al., 1988; Bottomley et al., 1990) that SST observations after World War II are not subject to bias effects. This statement is difficult to rationalize for the Indian Ocean in view of the discrepancies between the SST and ART trends during 1946-1976 (illustrated in Fig. 6) if we accept the hypothesis of the correctness of the ART data during this period (this hypothesis will be verified in Section 4). In fact, recent investigations show that the transition period between the two broad categories of instruments for measuring the SST was not completed even by 1970 (Folland et al., 1993) and so, one wonders if this is not the main cause of the discrepancies between the SST and ART during 1946-1976. On the other hand, the disagreement between the SST and ART series is mostly confined to the 1968-1974 period (Fig. 6). A careful examination of the SST raw data before the quality controls applied in paragraph 3.a reveals the presence of an unacceptable number of unreasonable wild SST measurements (between $35^{\circ} \mathrm{C}$ and $40^{\circ} \mathrm{C}$, these reports are mainly confined along the shipping routes from Madagascar to Sumatra and from Sumatra to the Northern Arabian Sea) for all the months of the 1968-1974 interval. This result leads to the possibility that some erroneous decks contaminate our database for the SST parameter during 19681974. In this context, it is noteworthy that Folland et al. (1993) state that the bucket/engine-intake flags in the UK Meteorological Office Main Marine Data Band (MOMMDB) indicate "a sudden, very large and persistent change in the ratio of bucket to nonbucket observations between December 1974 and January 1975", and are therefore unreliable before January 1975. This last date matches exactly the end of the contamination of our SST dataset by the wild measurements. All these facts suggest the presence of suspect decks in different marine datasets for the beginning of the 1970s and this can also explain the discrepancies between the SST and ART fields during the 1954-1976 period. In any case, the warming SST trend in the Indian Ocean during this interval seems largely artificial and not related to climatic fluctuations. This hypothesis is again corroborated by the absence of SLP trends during 1954-1976.

The changes in the trend and annual cycle components of the SST and ART time series around 1976 (Figs. 3 and 4) are also strongly suspect since the number of ship observations undergoes a big decrease around 1976. On the other hand, the high SLP anomalies observed after 1976 (Fig. 7) agree quite well with the SST and ART warming observed during the 1977-1986 decade. Since the same change is found in three independent datasets, this is a first indication that there is a real climatic change around this date despite the various deficiencies attending the SST, ART and SLP ship-measurements. Moreover, the same jump is also seen in other parameters such as wind and cloudiness in our files and have been noted by other researchers on COADS (Morrissey, 1990). Indeed, such a general phenomenon could be linked to the ENSO related highly anomalous weather conditions observed in the tropics after 1977 (Nitta and Yamada, 1989) and can therefore represent a real climatic change. In this respect, it should be emphasized that the SST and ART warmings, and the high SLP anomalies observed in the Indian Ocean after 1976 correspond exactly to the ENSO signature at the interannual time scale. A definitive answer about the origin of the 1976's discontinuity in our marine dataset will be also given in the next section. Finally, we note that the exact nature of the 1932's SLP jump remains still unsolved for the moment since this discontinuity is not clearly apparent in the SST and ART fields. 


\section{Comparison of Corrected Land Data with Marine Observations}

The idea of this section is to apply the X11 procedure on selected area-averaged long time series computed from our corrected land database and then to compare them with the X11's components derived from the marine dataset. This is one of the best way to check the reality of the "climatic changes" apparent in the marine dataset because land-based data are expected to be much more reliable than shipmeasurements, without speaking of the space/time sampling problem of the ship-data. Particularly, the trend components estimated from SLP and T measurements at land-based stations are expected to be far more reliable than their SLP, SST and ART marine counterparts since these land data have been also corrected for bias effects.

To enhance the quality of the comparison of the marine with land-based trends, the development of the land-recorded SLP and T X11's components follows the same procedure as used for the marine series. First, a climatology was estimated for each station/parameter during 1954-1976. All the available data during this time interval has been used to estimate as accurately as possible a climatology for each station and parameter. Monthly anomalies during 1900-1984 were then formed for each station/parameter relative to this climatology and averaged over the west coast of India, the east coast of India and over the whole Indian subcontinent by using the available data. Eleven coastal stations were selected from our land dataset to represent the west coast of India. This time series is designed to examine the consistency of the ship-observations in the east Arabian Sea domain (Fig. 2). Ten temperature and eleven SLP stations along the east coast of India were also chosen to corroborate trends from ship data in the Bay of Bengal. Finally, two grand averages of SLP and $T$ anomalies for the whole Indian subcontinent were formed. These two anomaly series will be compared to the whole Indian Ocean SLP, SST and ART time series examined in the last section.

These three area averaged time series for the SLP and $\mathrm{T}$ parameters were then processed similarly as the ship data by the X11 procedure (see Appendix B). Note that the ship data were also reprocessed by the X11 procedure by restricting the time series to 1900 1984 for the comparison, since the land data are only available for this time interval.

\section{4. a Comparison of ART and $T$ trends}

Figure 8 gives the trend components for the ART and $\mathrm{T}$ series. In the comparisons east Arabian sea/ west coast of India and Bay of Bengal/east coast of India, the marine and land series agree reasonably well indicating a warming trend during 1900-1939, no significant trend during 1945-1976 and a sudden warming beginning in 1977. This suggests that the systematic errors attending the ART fields do not greatly distort the true climatic trends and jumps during 1900-1984. The significance of the trends during 1900-1939 has been verified with the help of the Spearman rank correlation and Kendall Tau coefficients (see Appendix A) applied to both the marine and land anomaly series during this interval. All the statistics are significant to the 1\% level or more (Table not shown). It is noteworthy that the land trends match reasonably well the marine ones in the beginning of the 1940s. Thus, it appears that the warmth ART anomalies over the Indian Ocean during World War II are a blend of a true climatic happening (perhaps the well-known strong El Niño event of 1939-41) and of a probable change in observational practice (Bottomley et al., 1990). None of the land trend components suggest a shift from a pre-1940s mean climate state to a new post 1940 s mean state if we take into account these facts occurring during World War II. The agreement between the marine and land temperature series is especially good during the 1954-1976 interval, this is consistent with our suggestions that the ART series are far more reliable than the SST series and that the warming SST trend during this interval is not real.

Excluding the World War II period, the main discrepancies between the land and marine temperature trend components occur during the 1920-1940 interval for the comparisons between east Arabian Sea and west coast of India, Bay of Bengal and east coast of India, and also between the two grand series after 1976. Plausible reasons for such discrepancies are as follows.

Consider first the problem attending the 1920-1940 period. A possible cause for the relative discrepancy between the series during this period may come from the land series and not the ART marine fields. From the 1870 s to the $1930 \mathrm{~s}$, the $\mathrm{T}$ measurements in India were made by thermometers siting in thatched sheds (Parker and Folland, 1989). This seems to give higher temperatures than do Stevenson screen exposures by about $0.4^{\circ} \mathrm{C}$. Stevenson screen exposures became the new standard in India between 1930 and 1940 and some positive biases in the Indian $\mathrm{T}$ series can result from this change between the pre-1940s and post1940s data (Parker and Folland, 1989). Note that our corrections of the Indian temperature data reported in section 2 do not treat this problem, so this is a possible reason for the disagreement between the marine and land series during 1920-1940. The trend components computed from the series representing the east Arabian Sea and the west coast of India are consistent with the existence of a positive bias in the land data since the $\mathrm{T}$ trend component is higher than the ART trend during 1900-1940. Moreover, the difference between the two curves during 1920-1940 is of the same order as the possible bias in the land 


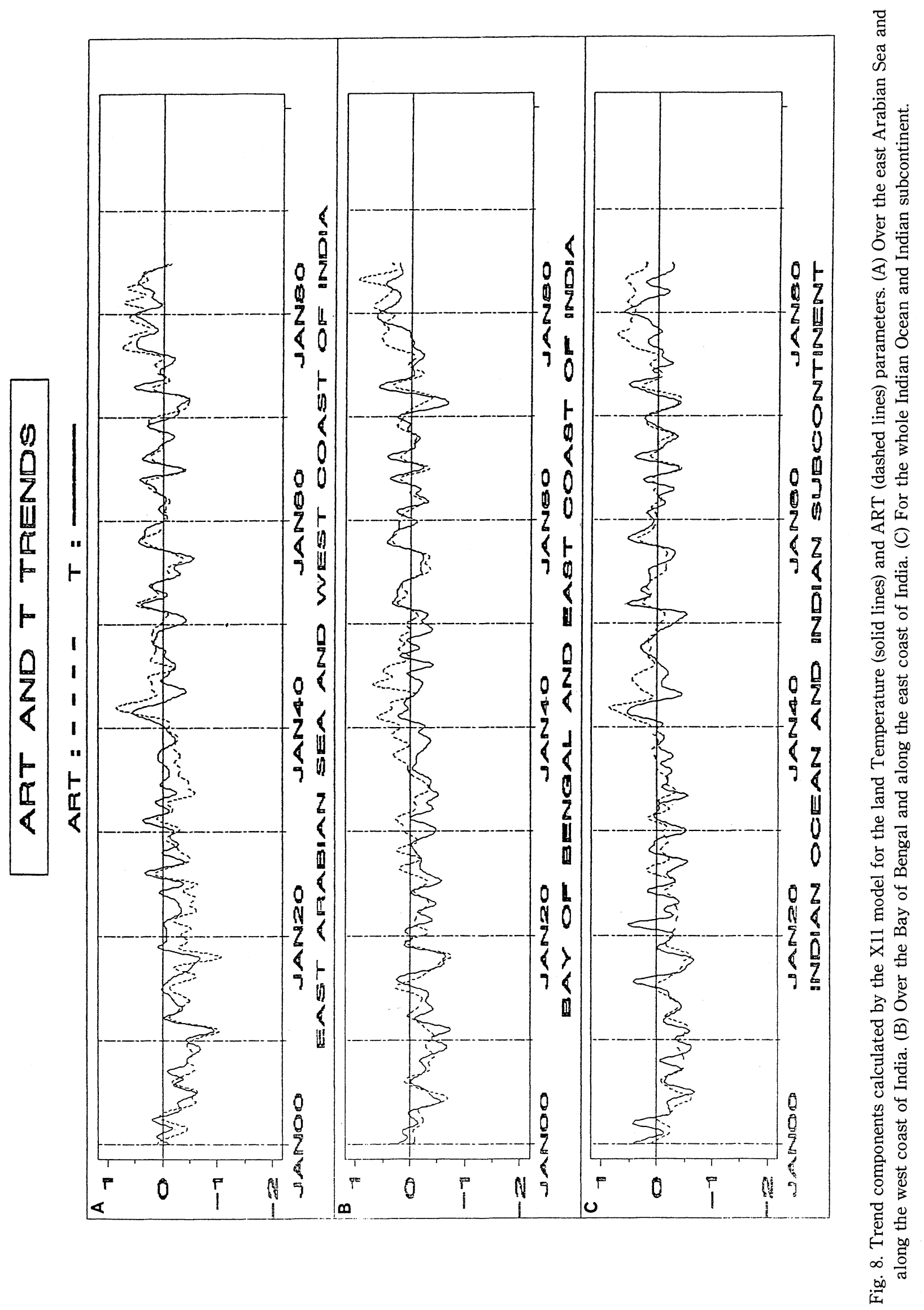




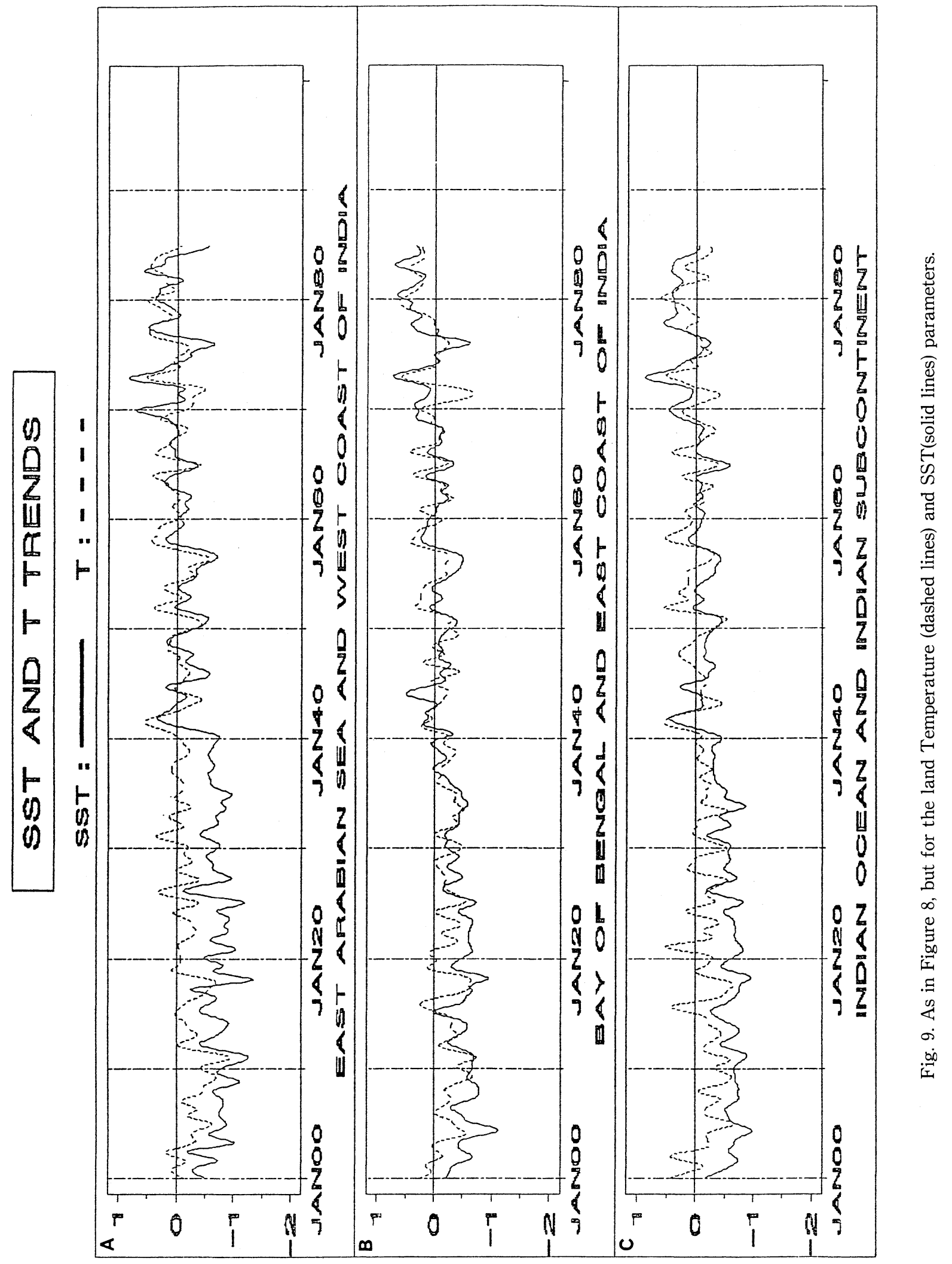


data. However, both the comparisons between the Bay of Bengal and the east coast of India, and between the two grand series are not consistent with the suggestion of Parker and Folland since in one case the $\mathrm{T}$ trend is significantly lower than the ART one and in the other case the two trend series agree reasonably well. Since the possible bias in the land data attends all the stations in the Indian subcontinent, the discrepancy should be particularly significant for the grand series, but the reverse situation is observed with a good agreement between the two trends, and the land temperatures being lower than the ART measurements during 1920-1940. Thus, we conclude that the problem during this period is likely linked to the ART marine data and not to the land data.

Consider now the discrepancy between the two grand series for the Indian Ocean and the Indian subcontinent after 1976 (Fig. 8). The marine trend component suggests a global warming in the Indian Ocean during 1977-1986, but no warming at all is suggested by the grand series for the subcontinent. This fact, plus the observation that the 1976-1986 decade is not well sampled over the Indian Ocean (see Figs. 3 and 4), seems to invalidate our suggestion of an important geophysical happening in the Indian region after 1976 and one may conclude that the ART fields are highly unreliable after 1976 due to a sampling bias. However, the trend series representing the coastal areas of the Indian subcontinent show a significant warming after 1976 and agree reasonably well with the ART trends despite the sampling problem attending the marine data after 1976. These apparently contradictory results suggest that the recent warming over the Indian Ocean is perhaps more linked to ocean dynamics or ocean-atmosphere interactions than to the possible influence of a general increase in the concentration of greenhouse gases since this warming does not affect the interior of the Indian subcontinent. In any events, the comparison between the coastal stations and the marine data corroborates the existence of a shift in the mean climate state over the Indian Ocean after 1976.

\section{4.b Comparison of SST and $T$ trends}

The comparisons between the SST and T trend components for the three domains are presented in Fig. 9. The mutual consistency between these trends is far less convincing than the ones reported between the ART and T trends. This tends to confirm our suspicion about the Indian Ocean SST data. The strong bias resulting from the systematic conversion from bucket to injection measurements around 1940 is clearly seen in the three comparison panels of Fig. 9. Note that the amplitude of the bias affecting the pre-1940s data is strongly geographically dependent and that the change seems to occur around 1930 in the Bay of Bengal. This shows that the detailed and geographically varying corrections of the pre-1940 SST data undertaken in the recent UKMO SST dataset are well-founded. However, the disagreement between the SST and T trend components is not limited to the pre- 1940 period and Fig. 9 corroborates the evidence that the recent SST data need also important adjustments. During the 19461976 interval, which is the main basis for the recent studies focusing on interannual and decadal scale variations in the Indian Ocean, the discrepancies between the SST and T trend components are similar to those observed between the SST and ART series (Fig. 6). As already mentioned in section 3, these discrepancies seem to be explained by both a gradually increase of the number of injection measurements relative to uninsulated bucket observations during the recent decades and the merging of source decks with different properties during the 1968-1974 interval, some of these decks containing unreasonably wild SST observations. In any event, the agreement between the ART and T trends is so good during 1954-1976 (Fig. 8) that there is little doubt about the fact that the artificial errors are linked to the SST data and not to the ART or T series. After 1976, the results are almost identical to those described above for the ART and T fields, suggesting a different temperature evolution pattern over the Indian Ocean and the Indian subcontinent.

\section{4.a Comparison of SLP marine and land trends}

The comparison between the SLP coastal and marine trends is given in Fig. 10. The overall consistency is surprisingly very good during the whole period and for the three comparisons. Indeed, this agreement is much better than those observed between the SST, ART and T trends. This provides strong support for our corrections of the SLP land data and suggests that the various sources of error attending SLP measurements aboard ship have not strongly deteriorated the true decadal variations of the SLP fields over the Indian Ocean. All the comparisons suggest the existence of a decreasing SLP trend from 1900 to 1939 in both the Indian Ocean and the Indian subcontinent. The significance of these trends has been verified with the Spearman rank correlation and Kendall Tau coefficients (see Appendix A). It is noteworthy that all the trend components agree during 1977-1984 and that both the Indian Ocean and the Indian subcontinent have experienced high SLP anomalies after 1976, since these results have direct implications for determining the origin of the SST and ART fluctuations during the recent decades. This is a new important confirmation of the specificity of the post-1976 period and a new indication that a sudden climatic change has occurred around 1976. Finally, the facts that the SLP marine and land trends are discordant during 1920-1930 for the two grand anomaly series, and during 1932-1945 for the 


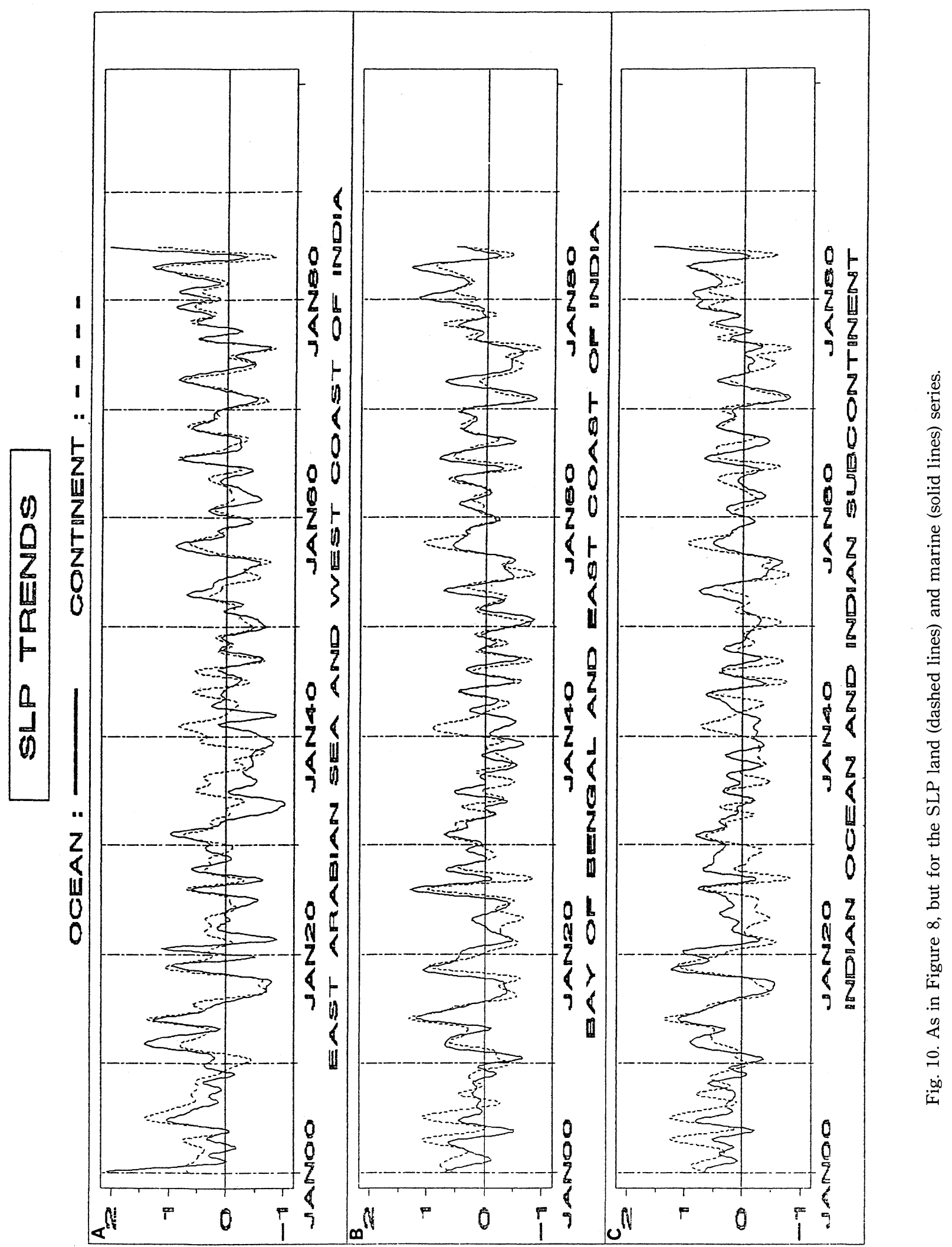




\section{SST EOFI (29\%)}

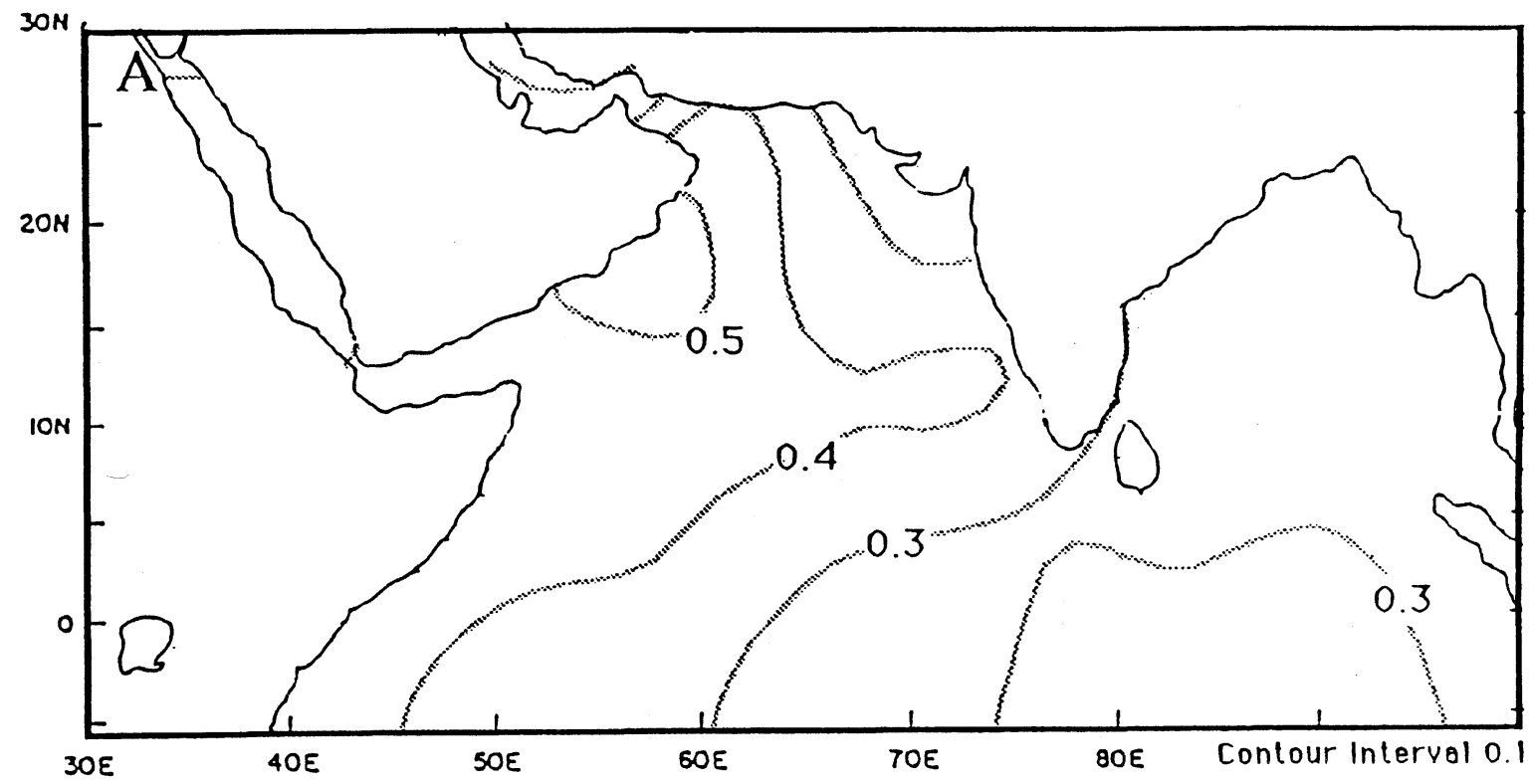

ART EOFI (23.5\%)

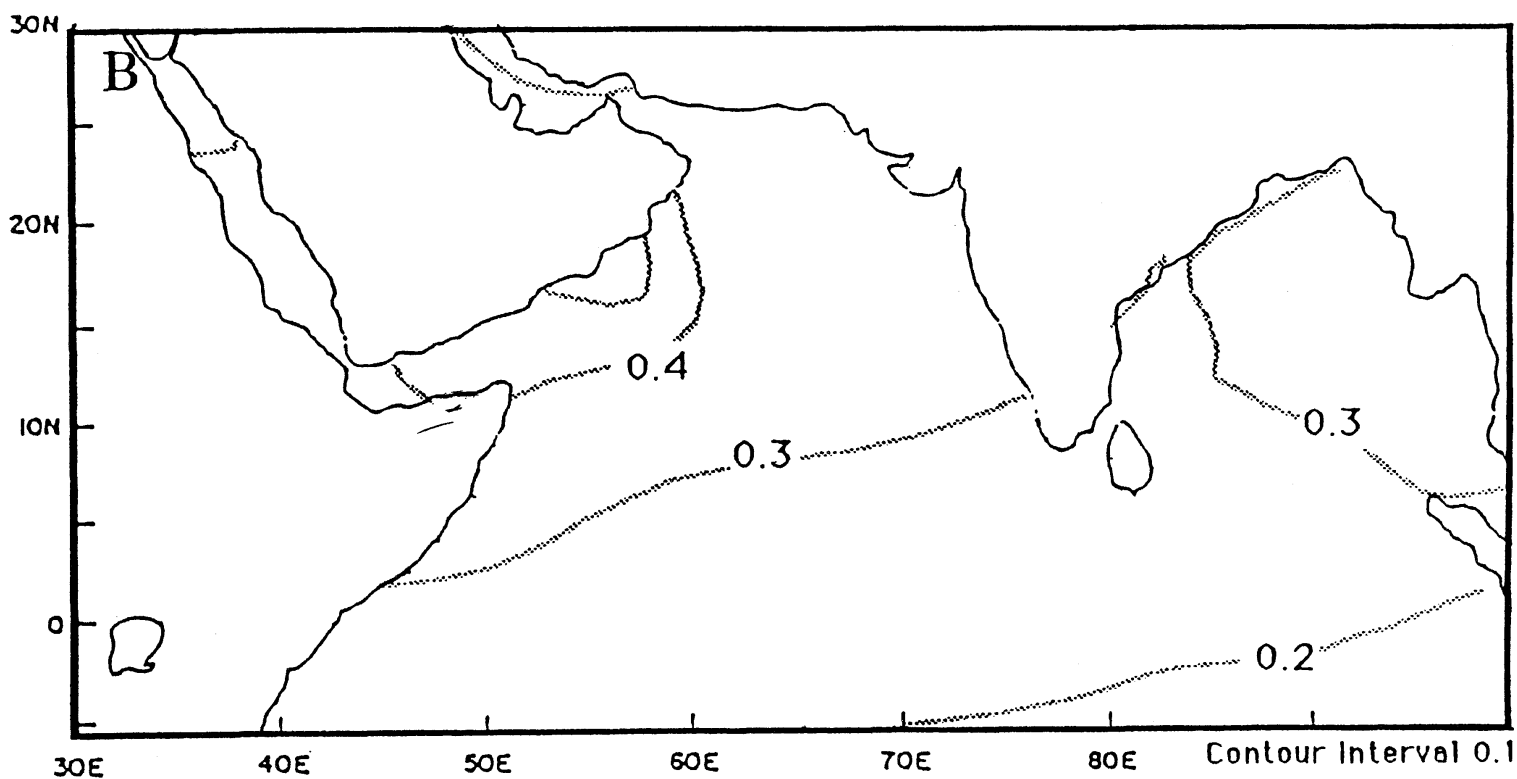

Fig. 11. (A) Spatial pattern of the first eigenmode of the objectively analyzed SST fields during 1954-1976. The number in parentheses shows the percentage of variance accounted for by this mode. (B) Same as in (A), but for the ART parameter.

comparison between the east Arabian Sea and the west coast of India strongly questions the 1932's jump in the SLP marine fields. Moreover, no discontinuity is apparent around this date in the three SLP land trend components given in Fig. 10. Both results suggest that the SLP marine data need some adjustments in the 1920-1940 interval for reducing the 1932' $\mathrm{s}$ artificial bias.

\section{Consequences of the Recent SST Errors for Interannual Studies}

In this section, we will outline the consequences of the post-1940s artificial errors of the SST fields for studies focusing on interannual monsoon variability. First, all the SST and ART fields during the 19541976 period (which is the main basis of nearly all the studies trying to assess the relationships between the Indian Ocean SST and the Indian monsoon) were 

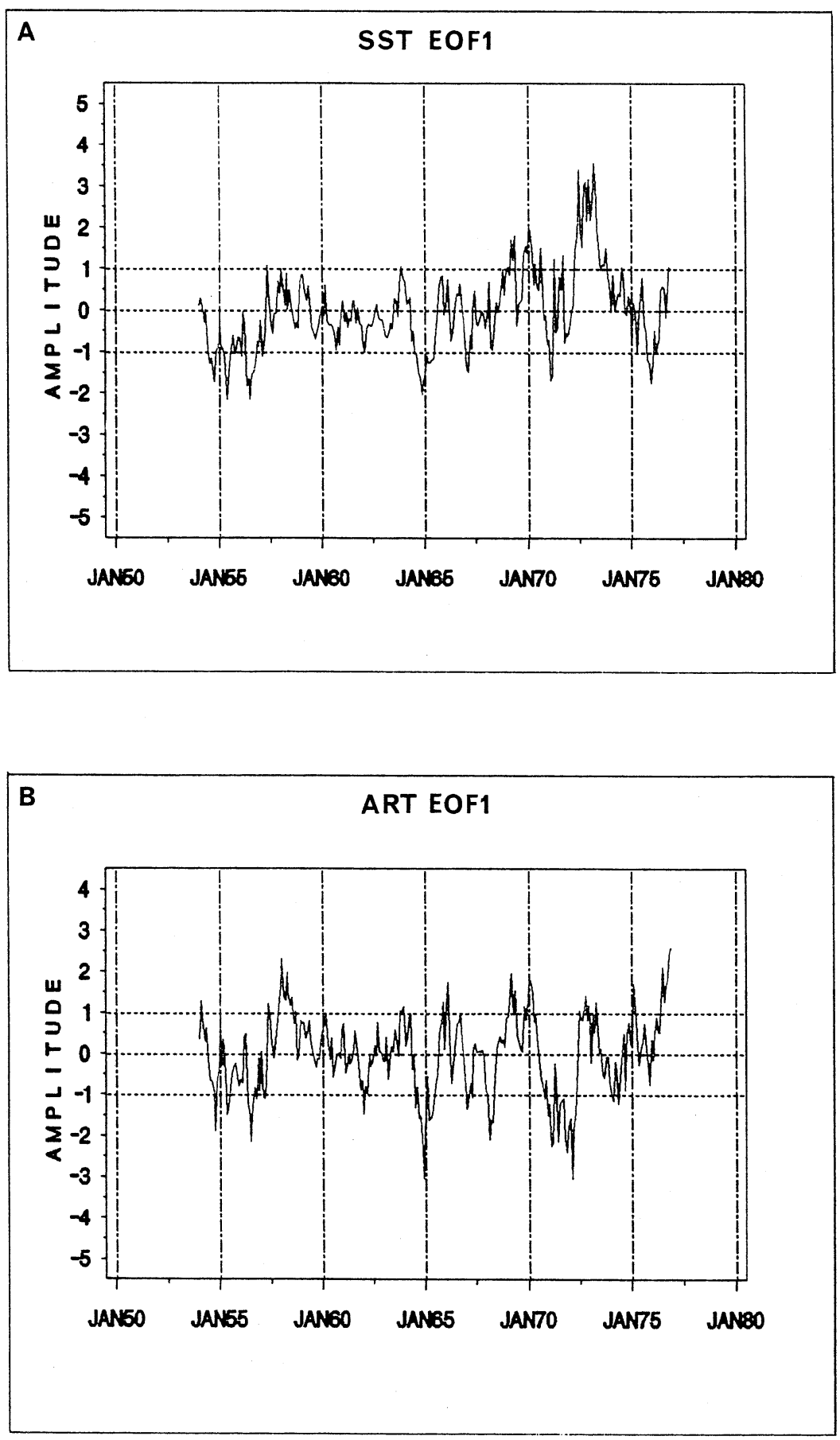

Fig. 12. (A) EOF1 time amplitude function of the first eigenmode of the objectively analyzed SST fields during 1954-1976. (B) As in (A), but for the ART parameter.

objectively analyzed with a successive correction method taking climatological means from atlas as a first guess field (Cadet and Diehl, 1984). This method spatially smoothes the different fields by filling the data-void areas with reasonable values which are a linear combination of climatology and anomalies observed in the neighborhood of each grid point. Moreover, this scheme is very effective in removing all the systematic errors due to the shift of the main shipping routes occurring in the $1954-1976$ period, as well as spurious values observed at some grid points (Terray, 1992). In doing so, we minimize all the various problems attending the SST and ART shipdata, excepted the one linked to the artificial errors contaminating the SST measurements during this period. Thus, any discrepancy between the space/ time variability of the two fields is likely to be due to this contamination or to the inherent noise of the ART data (see Table 4). Finally, to focus only on the effects of the SST contamination, the Empirical 
Table 7. Spearman's correlation and Kendall's Tau calculated on the leading EOF time amplitude functions of the SST and ART fields during 1954-1976. The coefficients exceeding the $5 \%$ and $5 \%$ probability level are followed by one star $\left(^{*}\right)$ and two stars $\left({ }^{* *}\right)$, respectively.

\begin{tabular}{|c|c|c|c|}
\hline \multicolumn{4}{|c|}{ TABLE 7} \\
\hline \multicolumn{4}{|c|}{$\begin{array}{c}\text { TREND ANALYSIS OF THE EOF AMPLITUDE } \\
\text { FUNCTIONS OF THE SST AND ART FIELDS } \\
\text { DURING 1954-1976 }\end{array}$} \\
\hline VARIABLE & $\overline{\mathrm{EOF}}$ & $\begin{array}{l}\text { SPEARMAN'S } \\
\text { CORRELATION }\end{array}$ & $\begin{array}{c}\text { KENDALL's } \\
\text { TAU }\end{array}$ \\
\hline SST & 1 & $0.37^{* *}$ & $0.26^{* *}$ \\
\hline ART & 1 & -0.09 & -0.06 \\
\hline
\end{tabular}

Orthogonal Function (EOF) method has been applied to the ART and SST monthly anomalies derived from the objectively analyzed fields and detailed attention will be given only to the leading EOFs of each parameter. The EOF analysis has been restricted to the grid points north of $6^{\circ} \mathrm{S}$ Latitude because the data in the Southern Indian Ocean are too sparse to give reliable objective fields.

Fig. 11 presents the first EOFs of the SST and ART anomaly fields during 1954-1976. Fig. 12 gives the time amplitude function of these first EOFs. The strong trends contributing to the SST fields are clearly seen on Fig. 12. As a statistical check, the Spearman rank correlation and Kendall Tau coefficients (see Appendix A) for the leading EOF time series of each field are reported in Table 7. It is clear that the characteristics of the SST and ART trends in the analyzed fields are rather different during 1954-1976, thus corroborating the results of our previous trend analysis on the raw-data: The first EOF of the SST fields (Fig. 12 and Table 7) shows a strong trend to warmer temperature over the whole domain (significant at the $5 \%$ level, see Table 7), but the first EOF of the ART fields does not include any trend at all despite the fact that both EOFs are of the same sign over nearly all the domain. Moreover, the spatial patterns described by these leading EOFs of the SST and ART series are quite different (Fig. 11). These facts suggest that the artificial trends not only destroy the long-term behavior of the SST fields, but also contaminate the interannual signal which can be observed in the series. It is often stated that ocean data, when averaged over large regions, are adequate for the study of short-term interannual variability, even when they are contaminated by spurious trends (Wright, 1986). In the light of Figs. 11 and 12, this statement seems invalid for the Indian Ocean, because very little signal remains on the various fields after the removal of the annual cycle. Indeed, this weak interannual signal is roughly of the same level of amplitude as the errors resulting from the artificial trends $\left(0.5^{\circ} \mathrm{C}\right)$ during the $1954-1976$ period. These new results shed some light on the origin of the disappointingly large number of contradictory results which have been obtained recently about the role of the Indian Ocean SST variations in the Indian summer monsoon (Shukla and Misra, 1976; Weare, 1979; Cadet and Diehl, 1984; Wu and Hastenrath, 1986; Shukla, 1987): most of these studies used the SST series without any kind of corrections or only a mild transformation of the data. A new analysis of the SST fields over the Indian Ocean seems to be required to fully assess their real impact on the interannual variability of both the Indian summer monsoon and the global climate.

\section{Conclusions}

In order to reach reliable results in future monsoon research, a tedious work was undertaken here to document many systematic errors which have occurred on both the land-records and the ship-observations in the Indian sector during the 1900-1986 period.

(i) A detailed examination of the NCAR's WMSSC collection has revealed that a disappointingly great number of spurious jumps contaminates most of the SLP monthly Indian time series. A close inspection of this problem and of the published sources contributing to the WMSSC collection has revealed that most of the errors result from mistakes at NCAR when the various data sources have been compiled.

For the 1900-1960 period, many errors result simply from the non-application of the careful corrections suggested in the WWRs volumes to take care of the slight changes of the observation time during this interval. Moreover, many discontinuities occur in phase with changes in the data-sources merged into the tapes. The most important discontinuity of this type is observed in 1960 with the change from the WWRs collection to the MCDW volumes. The specific cause of this systematic error is simply that the SLP values published in the WWRs have been recorded mainly at $8 \mathrm{H} 30$ IST or $8 \mathrm{H}$ ILT whereas the values reported in the MCDW collection have been calculated with the formula $(8 \mathrm{H} 30+17 \mathrm{H} 30) / 2$ IST. Taking into account the diurnal SLP cycle over the Indian subcontinent, many correction formulae were derived for adjusting the SLP time series. It has been shown statistically that the adjustments increase the integrity of the records. Some corrections were also applied to the temperature's data. The main problem in this collection is now the missing gaps which affect most of the series.

(ii) A preliminary investigation into the SST, ART and SLP measurements recorded over the Indian Ocean during the 1900-1986 period indicates that these data are also affected by spurious jumps and artificial trends.

The main spurious discontinuities observed during 
the $1900-1986$ period are 1932 for the SLP fields, 1940 for both the SST and ART series, and 1954 for the SST series in the east Arabian Sea and the Bay of Bengal. It should be emphasized that these sudden changes have been identified by some workers $(e . g$., $\mathrm{Fu}$ and Fletcher, 1988) as transition periods from one state to another of the monsoon system. However from our dataset, all these dates correspond also to transition periods between the different "sourcedecks" contributing to the marine historical record. In any case, we strongly suggest that the announcement of climatic changes over the Indian Ocean around these dates must await a much more careful examination with multiple intercomparisons between independent data sources and detailed analysis of the "source-decks"contributing before and after the date of the "climatic changes". The work required is considerable if at all possible.

In the same fashion, a preliminary analysis has raised some doubts about the climatic origin of a warming SST trend which is observed in the Indian Ocean during the 1954-1976 period. Again, this contamination is thought to be due to the mixing of "source-decks" with different characteristics. Moreover, it has been demonstrated that the instrumental errors not only affect the long-term behavior of the SST fields during 1954-1976, but also destroy the integrity of the weak interannual climatic signals which can be present into the time series. This fact provides an explanation for the little success met by investigators trying to link the SST interannual variations in the Indian Ocean with the quality of the Indian Monsoon. A true assessment of the relationships between Indian Ocean SST anomalies and the interannual variability of both the summer monsoon and the global climate must await a more careful examination because the interannual SST signal has roughly the same magnitude as the instrumental errors. This does impugn the detectability of the true impact of the SST fields, if the SST anomaly series are not properly adjusted for both the artificial trends and the inhomogeneities contaminating the data.

However, the most crucial problem attending the Indian Ocean ship data is perhaps the existence of strong sampling biases towards specific months. This indicates that the monthly means for some calendar months (winter) are much less reliable than those for other months and that substantial biases in resolution of the annual cycle can be expected for all the parameters. Again, this sampling problem is more pronounced in the SST fields. The SLP and ART parameters seem less affected, but probably only because the basic natural and artificial noise is much more important for these two parameters.

It is often stated that the pre-World War II shipdata are less reliable than the post-1945 observations. From our experience, the post-1945 data over the
Indian Ocean are nearly of the same bad quality than the pre-1945 records. The wild SST measurements sampled in the Indian Ocean during 1968-1974 furnish an extreme illustration to this assertion. Or to say the things more optimistically, the data of the first part of this century are as good as those of the last part, but the problems involved are rather different. Before World War II, there was no generally recognized observational practices for measuring many meteorological parameters. Moreover, the number of individual decks that make up this part of the marine record is less important. Over some areas the scarcity of the ship-reports come as a second difficulty. These facts lead to a high-level of noise in the pre1940 data as well as to spurious discontinuities in the time series of many parameters during 1900-1940 when source-decks with different properties are merged into the historical marine dataset. Note on the other hand that the sampling for some areas as the Bay of Bengal or the east Arabian Sea is better before World War II than after. This result is contrary to the common assertion that the data before 1950 are too sparse to be worth study. By contrast, coding practices and observation techniques have been progressively formalized by each voluntary observing fleet, and the number of different source decks merged in the marine dataset has largely increased after the 1940s (Ramage, 1987; Woodruff et al., 1987). The net effect of these two facts seems to have been a decrease of the number of spurious jumps and the apparition of instrumental trends in the marine dataset during the recent decades. This last effect is particularly well illustrated by the steady warming artifical trend which contaminates the SST fields over the Indian Ocean during 19541976. The spurious trend toward strengthening winds in many regions after World War II (Ramage, 1987; Cardone et al., 1990), which is a consequence of the increasing proportion of anemometer-equipped ships, is another good illustration of this phenomenon. Finally, the very small amount of data during World War II and the overall bad quality of the ship-reports during this sample period separating the two different parts of the historical marine record must be emphasized.

(iii) A detailed comparison between SLP and temperature trends over the Indian Ocean and the Indian subcontinent has however suggested the existence of some significant decadal-scale climatic fluctuations during the 1900-1986 period. These true geophysical happenings include prominently a progressive warming temperature trend and SLP decrease over both the land and the ocean during 1900-1939, and a sudden warming in the Indian Ocean after 1976. This recent warming does not affect the interior of the Indian subcontinent and is in phase with persistent high SLP anomalies for the whole Indian sector. This is in accordance with the persistence or more frequent 
occurrences of ENSO-type conditions in the tropics after 1976 (Wolter and Hastenrath, 1989; Nitta and Yamada, 1989). Note however, that the suggestion of these authors that the warming over the Indian Ocean started as earlier as in the 1950 s seems erroneous since this trend is linked to the artificial errors discussed above. Indeed, both the more trustworthy ART fields (as far the Indian Ocean is concerned) and the coastal temperature measurements indicate on the contrary a slight cooling trend in the north Indian Ocean for the 1954-1976 period. This corroborates the evidence of a shift in mean state of the SST fields after 1976. It is very intriguing to note that the warming trends of temperature in the Indian area are accompanied by a SLP decrease during 1900-1939 and positive SLP anomalies after the late 1970s. However, these observations seem contradictory if, and only if, we accept the hypothesis that these decadal variations have the same origin and this is not a strong hypothesis since the space-time characteristics of these warming tendencies are quite distinct.

Provided that the marine observations can be successfully corrected, the datasets described in this paper will certainly give new insights into the interannual variability of the Indian monsoon and its relations to the ENSO phenomenon in future research, because they appear particularly well designed for highlighting the space-time evolution of the low-frequency climatic signals over the Indian Ocean during a longer period (1900-1986) than currently available.

\section{Acknowledgements}

The author would like to thank sincerely Dr. D. L. Cadet for giving him most of the basic dataproducts used in this study and Dr. D. E. Parker for a careful reading and judicious comments on an earlier version of this paper. I like also to thank the reviewers and Pr. T. Yasunari for constructive comments which helped to clarify this paper. Some of the results presented in this paper represent part of the author's Ph.D. supported by a Grant-in-Aid obtained through Université Paris V II (département de Géographie), France. Some of the processing has been done at Laboratoire de Météorologie Dynamique of CNRS (Palaiseau, France) and this financial support was vital for this research. This research was also supported in part by a Grant-in-Aid for Scientific Research for JSPS Post-Doc fellowship and by a Grant-in-Aid for Scientific Research No 05452077 from the Ministry of Education and Culture of Japan for 1993.

\section{Appendix A}

\section{Non-Parametric Tests}

1)The Kruskal-Wallis test
The Kruskal-Wallis test is a non-parametric procedure which is powerful for detecting location shifts in a sample. The test is derived by examining the probability distribution of a linear combination of the ranks of the observations under the null hypothesis that all the values are sampled from the same continuous distribution.

First, it is assumed that the sample can be divided a priori into $m$ groups. Then, the procedure ranks the sample's values from smallest to largest, assigning the rank 1 to the smallest observation, 2 to the next largest, and so on up to rank $n$, the number of nonmissing observations in the sample. Let $\mathbf{R}_{i}$ denotes the mean rank in the sample of the $n_{j}$ observations in the ith group. Then, the Kruskal-Wallis statistic is

$$
\mathbf{W}=12 \sum_{i=1}^{m} n_{i}\left(\mathbf{R}_{i}-\mathbf{R}\right)^{2} / n(n+1)
$$

where $\mathbf{R}$ is the grand mean rank in the sample. Under the null hypothesis that all the observations in the sample are drawn from the same continuous population, $\mathbf{W}$ is asymptotically distributed as $x^{2}{ }_{m-1}$ as all $n_{j}$ tend to infinity (Conover, 1980). This approximation has been used to derived the probability level of the tests computed in this paper. When this probability level is sufficiently small, we reject the null hypothesis and conclude that observations in one or more groups have slipped to the left or to the right ( $e$. $g$., these observations do not come from the same distribution as the other values in the sample). For more details on the Kruskal-Wallis test, see Conover (1980).

\section{2) The Spearman rank correlation coefficient}

The Spearman coefficient, $\mathbf{R}_{s}$, of two variables is simply the correlation of the ranks of the data

$$
\begin{aligned}
\mathbf{R}_{s}= & \sum_{i=1}^{n}\left[R\left(x_{i}\right)-\overline{\mathrm{R}}(x)\right]\left[\mathrm{R}\left(y_{i}\right)-\overline{\mathrm{R}}(y)\right] / \\
& \sqrt{\sum\left[\mathrm{R}\left(x_{i}\right)-\overline{\mathrm{R}}(x)\right]^{2}} \sqrt{\sum\left[R\left(y_{i}\right)-\bar{R}(y)\right]^{2}}
\end{aligned}
$$

where $R\left(x_{i}\right)$ is the rank of the $x_{i}$ value, $R\left(y_{i}\right)$ is the rank of the $y_{i}$ value, and $\bar{R}(x)$ and $\bar{R}(y)$ are the means of the $R\left(x_{i}\right)$ and $R\left(y_{i}\right)$, respectively (both equal to $n+$ $1 / 2$ ). The Spearman rank correlation coefficient can be used to assess the significance of a trend in a time series $x_{i}$ by computing the correlation between $R\left(x_{i}\right)$ and $i$, the chronological order. Under the null hypothesis that the $x_{i}$ are independently and identically distributed, the statistic

$$
(n-1)^{1 / 2} \mathbf{R}_{s} /\left(1-\mathbf{R}_{s}^{2}\right)^{1 / 2}
$$

is approximately distributed as a $t$-distribution with $n$-2 degress of freedom. For more details, see Conover (1980). 


\section{3) The Kendall Tau coefficient}

Kendall's Tau is a measure of dependence between two variables calculated from concordances and discordances. Concordance is measured by determining whether values of paired observations vary together (in concord) or differently (in discord). Let ( $x_{i}$, $\left.y_{i}\right), \mathrm{i}=1$ to $n$, be the values of two observed variables. For each of the $\left(\begin{array}{l}n \\ 2\end{array}\right)$ pairs of values, $\left\{y_{i}, y_{j}\right\}$, in the y sample, we say that the pairs $\left\{y_{i}, y_{j}\right\}$ and $\left\{x_{i}, x_{j}\right\}$ vary in concord if they are ranked in the same order, e.g., if

$$
\left\{\begin{array}{c}
y_{i}<y_{j} \text { and } x_{i}<x_{j} \\
\text { or } \\
y_{i}<y_{j} \text { and } x_{i}>x_{j}
\end{array}\right.
$$

The maximum number of concordances is $(n-1) n$ / 2. Let be $\mathbf{K}$, the difference between the number of concordances and discordances. Then, Kendall's Tau coefficient is defined as

$$
\mathbf{T}=2 \mathbf{K} /(n-1) n
$$

The normalization $\operatorname{by}(n-1) n / 2$ is used for restricting the range of $\mathbf{T}$ between -1 and 1 like an usual correlation coefficient. Kendall's Tau can also be used to assess the significance of a trend in a time series $x_{i}$ by computing the number of discordances and concordances between the $x_{i}$ 's and the chronological order i. Under the null hypothesis that the $x_{i}$ are independently and identically distributed, $\mathbf{T}$ is asymptotically distributed as $N(0,2\{2 n+5\} / 9 n\{n-$ $1\})$. See Conover (1980) for more details.

\section{Appendix B}

\section{The $X 11$ Procedure}

The X11 procedure is based on the assumption that seasonal fluctuations, $\mathbf{A}_{\mathrm{t}}$, can be measured in a time series of one variable, $\mathbf{X}_{t}$, and separated from trend, $\mathbf{T}_{\mathrm{t}}$, and irregular fluctuations, $\mathbf{I}_{\mathrm{t}}$. The seasonal component, $\mathbf{A}_{\mathbf{t}}$, is defined as intrayear variation that is repeated constantly or in an evolving fashion from year to year. The trend component, $\mathbf{T}_{t}$, includes variation due to the long-term trend and the lowfrequency oscillations in the time series. The irregular component, $\mathbf{I}_{t}$, is the residual variation. This gives the following classical decomposition of a time series

$$
\mathbf{X}_{\mathrm{t}}=\mathbf{T}_{\mathrm{t}}+\mathbf{A}_{\mathrm{t}}+\mathbf{I}_{\mathrm{t}}
$$

The main steps of the procedure are as follows if we assumed that $\mathbf{X}_{\mathrm{t}}$ is a monthly time series (Kendall and Ord, 1990):

(1) Subtract from the original series a centered 12-term moving average (that is, a 2 -term average of a 12-term average) to provide a preliminary estimate of $\mathbf{A}_{t}+\mathbf{I}_{t}$.

(2) Apply a 3-term moving average to this preliminary estimate of $\mathbf{A}_{\mathrm{t}}+\mathbf{I}_{\mathrm{t}}$ for each month separately to obtain an initial estimate of $\mathbf{A}_{\mathbf{t}}$.

(3) Subtract this initial estimate of $\mathbf{A}_{t}$ from the seasonal/irregular series obtained in step (1) to provide an estimate of $\mathbf{I}_{\mathbf{t}}$.

(4) Calculate a moving standard deviation from this estimate of $\mathbf{I}_{\mathrm{t}}$ and use it to assign a weight to each monthly value. These weights are then used for detecting outliers and to modify these extreme values in the estimate of the seasonal/irregular series obtained in step (1).

(5) Step (2) is repeated on this modified seasonal/ irregular series to obtain a new estimate of $\mathbf{A}_{t}$.

(6) Subtract this estimate of $\mathbf{A}_{t}$ from the original series to give a first estimate of $\mathbf{T}_{t}+\mathbf{I}_{t}$.

(7) Apply a 23-term weighted moving average to the series constructed in step (6) to give a second estimate of $\mathbf{T}_{\mathrm{t}}$ and subtract this estimate from the original series to give a second estimate of $\mathbf{A}_{t}+\mathbf{I}_{t}$.

(8) Steps (2)-(6) are repeated with this seasonal/ irregular series to give a refined estimate of $\mathbf{T}_{t}+\mathbf{I}_{t}$.

(9) The procedure performs a third and final iteration by repeating steps (7)-(8) on this refined estimate of $\mathbf{T}_{\mathrm{t}}+\mathbf{I}_{\mathrm{t}}$ to give the final estimates of $\mathbf{T}_{\mathrm{t}}, \mathbf{A}_{\mathrm{t}}$ and $\mathbf{I}_{\mathrm{t}}$.

\section{References}

Barnett, T.P., 1984: Long-term trends in surface temperature over the oceans. Mon. Wea. Rev., 112, 303-312.

Barnett, T.P.,1991: The interaction of multiple time scales in the tropical climate system. J. Climate, 4, 269-285.

Bottomley, M., C.K. Folland, J. Hsiung, R.E. Newell, and D.E. Parker, 1990: Global ocean surface temperature atlas "GOSTA". Joint project of the UK Meteorological Office and Massachusetts Institute of Technology, 20 pp., 313 plates, HMSO.

Cadet, D.H., and B.C. Diehl, 1984: Interannual variability of surface fields over the Indian Ocean during recent decades. Mon. Wea. Rev., 112, 1925 $-1935$.

Cardone, V.J.,J.G. Greenwood, and M.A. Cane, 1990: On trends in historical marine wind data. J. Climate, 3, 113-127.

Conover, W.J., 1980: Practical nonparametric statistics. John Wiley \& Sons, New York.

Folland, C.K., D.E. Parker, 1988: Observed variations of sea surface temperature. Proc. NATO Advanced Research Workshop on Climate-Ocean interaction. Kluwer Academic Publisher, Oxford, UK.

Folland, C.K., R.W. Reynolds, M. Gordon and D.E 
Parker, 1993: A study of six operational sea surface temperature analyses. J. Climate, 6, 96 $-113$.

Fu, C., and J. Fletcher, 1988: Large signals of climatic variation over the ocean in the asian monsoon region. Adv. in Atm. Sci., 5, 389-404.

Hastenrath, S., and K. Wolter, 1992; Large-scale patterns and long-term trends of circulation variability associated with Sahel rainfall anomalies. J. Meteor. Soc. Japan, 70, 1045-1055.

Kendall, M.G., and J.K. Ord, 1990: Time series. Griffin, London.

Krishnamurti, T. N., 1971: Tropical east-west circulations during the northen summer. J. Atnos. Sci., 28, 1342-1347.

Morrissey, M.L., 1990: An evaluation of ship data in the Equatorial Westerm Pacific. J. Climate, 3, 99 -112 .

National Climate Data Center, 1968: TDF-11 Reference Manual. [available from NCDC, Asheville, North Carolina, US] .

Nitta, T., and S. Yamada, 1989: Recent warming of tropical sea surface temperature and its relationship to the northern hemisphere circulation. $J$. Meteor. Soc. Japan, 67, 375-383.

Parker, D.E., and C.K. Folland, 1989: Worldwide surface temperature trends since the mid-19th century. Proceedings of Dept. of energy workshop on "Grenhouse gas-induced climate change", 8-12 may 1989, Mass.

Ramage, C.S., 1984: Can shipboard measurements reveal secular changes in tropical air-sea heat fluxes?. J. Climate Appl. Meteor., 23, 187-193.

Ramage, C.S., 1987: Secular change in reported surface wind speeds over the ocean. J. Climate Appl. Meteor., 26, 525-528.

Rao, K.G., and B.N. Goswami, 1988: Interannual variations of Sea Surface Temperature over the Arabian Sea and the Indian Monsoon: A new Perspective. Mon. Wea. Rev, 116. 558-568.

Rasmusson, E.M., X. Wang and C.F. Ropelewski, 1990: The biennial component of ENSO variability. J. Mar. Sci., 1, 71-96.

Shea, D.J., and W.L. Spangler, 1985: NCAR's global monthly surface station data set. Preprints, Third Conf. on Climate Variations: Symp. on Contemporary Climate: 1850-2100, Los Angeles. Amer. Meteor. Soc.

Shukla, J., 1987: Interannual Variability of Monsoons. Monsoons, Chapter 14, J. S. Fein and P. L. Stephens, Eds. John Wiley \& Sons, pp. 339-463.

Shukla, J., and B.M. Misra, 1977: Relationships between sea surface temperature and wind speed over the central Arabian Sea, and monsoon rainfall over Indea. Mon. Wea. Rev., 105, 798 -1002 .

Smithsonian Institution, 1927: World Weather Records (all data up to and including 1920). Vol. 79,
Washington D.C.

Smithsonian Institution, 1934: World Weather Records, 1921-1930. Vol. 90, Washington D.C.

Smithsonian Institution, 1947: World Weather Records, 1931-1940. Vol. 105, Washington D.C.

Terray, P., 1992: Interannual Variability of Indian Summer Monsoon and Long-Range Forecasting of Rainfall over India. Ph. D. dissertation, University Paris V II, Paris (in French).

Trenberth, K.E., and D.J. Shea, 1987: On the Evolution of the Southerm Oscillation. Mon. Wea. Rev., 115, 3078-3096.

US Department of Commerce, 1959: World Weather Records, 1941-1950. Weather Bureau, Washington D.C.

US Department of Commerce, 1967: World Weather Records, 1951-1960. Weather Bureau, Washington D.C.

US Weather Bureau, 1961-1984: Monthly Climatic Data for the World. ESSA/NOAA.

Weare, B., 1979: A statistical study of the relationships between ocean surface temperatures and the Indian monsoon. J. Atmos. Sci., 36, 2279-2291.

Wolter, K., and S, Hastenrath, 1989: Annual cycle and long-term trends of circulation and climate variability over the tropical oceans. J. Climate, 2 , 1329-1351.

Woodruff, S.D., R.J. Slutz, R.L. Jenne, and P.M. Steurer, 1987: A comprehensive oceanatmosphere data set. Bull. Amer. Meteor. Soc., 68, 1239-1250.

Wright, P.B., 1986: Problems in the use of ship observations for the study of interdecadal climate changes. Mon. Wea. Rev., 114, 1028-1034.

Wright, P.B., 1988: On the reality of climatic changes in wind over the Pacific. J. of Climatology, 8, 521 -527 .

Wu, M.C., S. Hastenrath, 1986: On the interannual variability of the Indian monsoon and the Southern Oscillation. Arch. Meteor. Geophys. Bioklim., Serie B, 36, 239-261.

Wulber, M.L., P. Spangler and L. Roy, 1984: World Monthly Surface Stations Climatology. NCAR, Scientific Computing Division, Boulder, USA.

Yasunari, T., 1990: Impact of Indian monsoon on the coupled atmosphere/ocean system in the tropical Pacific. Meteor. \& Atmos. Phys., 44, 29-41.

Yasunari, T., 1991: The monsoon year-A new concept of the climatic year in the tropics. Bull. Amer. Meteor. Soc., 72, 1331-1338. 


\title{
インド洋地域における気候データの評価
}

\author{
Pascal Terray \\ (筑波大学 地球科学系)
}

モンスーンシステムの年々変動ならびに10年スケールの変動を評価するために現在使用されている 陸地・海洋上の観測データに、気候因子によらない系統的誤差が存在していることを示した。1900-1984 年の期間でのNCARのWorld Monthly Surface Climatologyデータにおける主な不均質性はインド 亜大陸上の海面気圧 (SLP) の時系列にみられる。これらの不連続性は主に、データ編集時にサンプ ル期間によって観測時刻が異なっていることを考慮しなかったことと関連している。このような不連 続性の主な例として、World Weather RecordsからMonthly Climate Data for the Worldの編集に 変わった1961年があげられる。

系統的誤差は1900-1986年のインド洋における海面水温 (SST)、気温 (ART)、SLPの船舶観測デー 夕にもみられる。主な疑わしいジャンプは、SLPでは1932年、SST、ARTの両方では1940年、東アラ ビア海とベンガル湾のSSTでは1954年に生じている。また、1954-1976年のSSTのトレンドにも問題が ある。これらの不均質性に対する原因は正確には特定していないけれども、不連続の時期やトレンド は、海洋データセットに含まれてしまった“source-decks”の変化と対応していることに疑いの余地 がない。また、インド亜大陸の沿岸地域のSLP、地上気温観測の変動にも問題がある。最後に、イン ド洋上のサンプリングは1950年以降に強い季節依存性をもっているので、年変化における実質的な系 統誤差はすべてのパラメータに存在することが予想される。インド洋上の観測されたSSTの年々変動 にみられる多くの矛盾は上述のデー夕の問題と関係していると思われる。

しかしながら、陸地・海洋観測データのトレンドの比較から、1900-1986年の期間のインド地域にお いていくつかの有意な 10 年スケールの変動の存在が示唆された。これらの気候変化の主なイベントと して、1900-1939年の間の地上気温の上昇トレンドとSLPの減少傾向、そして1976年以降のインド洋の 突然の温暖化があげられる。この最近の温暖化は、インドの内陸部には影響しておらず、インド地域 全体の正のSLPアノマリーの持続と同位相である。これらは1976年以降のインド洋の気候変化 (Nitta and Yamada、1989) の事実を裏づけている。 